\title{
Biomass-burning impact on CCN number, hygroscopicity and cloud formation during summertime in the eastern Mediterranean
}

\author{
Aikaterini Bougiatioti ${ }^{1,2,3}$, Spiros Bezantakos ${ }^{4,5}$, Iasonas Stavroulas $^{3}$, Nikos Kalivitis ${ }^{3}$, Panagiotis Kokkalis ${ }^{2,11}$, \\ George Biskos $^{6,7}$, Nikolaos Mihalopoulos ${ }^{3,7,10}$, Alexandros Papayannis ${ }^{2}$, and Athanasios Nenes ${ }^{1,8,9,10}$ \\ ${ }^{1}$ School of Earth and Atmospheric Sciences, Georgia Institute of Technology, Atlanta, GA, USA \\ ${ }^{2}$ Laser Remote Sensing Unit, National Technical University of Athens, Zografou, Athens, Greece \\ ${ }^{3}$ ECPL, Department of Chemistry, University of Crete, Voutes, 71003 Heraklion, Greece \\ ${ }^{4}$ Department of Environment, University of the Aegean, Mytilene, 81100, Greece \\ ${ }^{5}$ Institute of Nuclear Technology and Radiation Protection, NCSR "Demokritos", 15310 Ag. Paraskevi, Athens, Greece \\ ${ }^{6}$ Faculty of Civil Engineering and Geosciences, Delft University of Technology, Delft $2728 \mathrm{CN}$, the Netherlands \\ ${ }^{7}$ Energy Environment and Water Research Center, The Cyprus Institute, Nicosia 2121, Cyprus \\ ${ }^{8}$ School of Chemical \& Biomolecular Engineering, Georgia Institute of Technology, Atlanta, GA, USA \\ ${ }^{9}$ Institute of Chemical Engineering Sciences (ICE-HT), FORTH, Patras, Greece \\ ${ }^{10}$ IERSD, National Observatory of Athens, P. Penteli 15236, Athens, Greece \\ ${ }^{11}$ IAASARS, National Observatory of Athens, P. Penteli 15236, Athens, Greece
}

Correspondence to: Aikaterini Bougiatioti (kbougiatioti@gmail.com) and Athanasios Nenes (athanasios.nenes@gatech.edu)

Received: 14 July 2015 - Published in Atmos. Chem. Phys. Discuss.: 10 August 2015

Revised: 26 February 2016 - Accepted: 24 May 2016 - Published: 14 June 2016

\begin{abstract}
This study investigates the concentration, cloud condensation nuclei (CCN) activity and hygroscopic properties of particles influenced by biomass burning in the eastern Mediterranean and their impacts on cloud droplet formation. Air masses sampled were subject to a range of atmospheric processing (several hours up to 3 days). Values of the hygroscopicity parameter, $\kappa$, were derived from CCN measurements and a Hygroscopic Tandem Differential Mobility Analyzer (HTDMA). An Aerosol Chemical Speciation Monitor (ACSM) was also used to determine the chemical composition and mass concentration of non-refractory components of the submicron aerosol fraction. During fire events, the increased organic content (and lower inorganic fraction) of the aerosol decreases the values of $\kappa$, for all particle sizes. Particle sizes smaller than $80 \mathrm{~nm}$ exhibited considerable chemical dispersion (where hygroscopicity varied up to $100 \%$ for particles of same size); larger particles, however, exhibited considerably less dispersion owing to the effects of condensational growth and cloud processing. ACSM measurements indicate that the bulk composition reflects the hygroscopicity and chemical nature of the largest particles (having a diameter of $\sim 100 \mathrm{~nm}$ at dry conditions) sampled. Based on
\end{abstract}

positive matrix factorization (PMF) analysis of the organic ACSM spectra, CCN concentrations follow a similar trend as the biomass-burning organic aerosol (BBOA) component, with the former being enhanced between 65 and $150 \%$ (for supersaturations ranging between 0.2 and $0.7 \%$ ) with the arrival of the smoke plumes. Using multilinear regression of the PMF factors (BBOA, OOA-BB and OOA) and the observed hygroscopicity parameter, the inferred hygroscopicity of the oxygenated organic aerosol components is determined. We find that the transformation of freshly emitted biomass burning (BBOA) to more oxidized organic aerosol (OOA-BB) can result in a 2-fold increase of the inferred organic hygroscopicity; about $10 \%$ of the total aerosol hygroscopicity is related to the two biomass-burning components (BBOA and OOA-BB), which in turn contribute almost $35 \%$ to the fine-particle organic water of the aerosol. Observationderived calculations of the cloud droplet concentrations that develop for typical boundary layer cloud conditions suggest that biomass burning increases droplet number, on average by $8.5 \%$. The strongly sublinear response of clouds to biomass-burning (BB) influences is a result of strong competition of $\mathrm{CCN}$ for water vapor, which results in very low 
maximum supersaturation ( $0.08 \%$ on average). Attributing droplet number variations to the total aerosol number and the chemical composition variations shows that the importance of chemical composition increases with distance, contributing up to $25 \%$ of the total droplet variability. Therefore, although BB may strongly elevate $\mathrm{CCN}$ numbers, the impact on droplet number is limited by water vapor availability and depends on the aerosol particle concentration levels associated with the background.

\section{Introduction}

Globally, biomass burning (BB) is a major source of atmospheric aerosols (Andreae et al., 2004). In the eastern Mediterranean, up to one-third of the dry submicron aerosol mass during the summer period consists of highly oxidized organic compounds (Hildebrandt et al., 2010). During JulySeptember, biomass-burning aerosol originates from longrange transport from southern Europe and countries surrounding the Black Sea (Sciare et al., 2008). Bougiatioti et al. (2014) showed that of the total organic aerosol (OA), about $20 \%$ is freshly emitted biomass-burning organic aerosol (BBOA), $30 \%$ is oxidized, processed OA originating from BBOA (BB-OOA), and the remaining $50 \%$ is highly oxidized aerosol that results from extensive atmospheric ageing. Hence, in terms of organic mass, during time periods of high biomass-burning activity, at least $50 \%$ of the aerosol can be attributed to BB emissions.

Aerosol liquid water content (LWC) is a key medium for atmospheric chemistry that also drives the partitioning of soluble organic vapors to the particle phase (Carlton and Turpin, 2013). LWC is a prime modulator of aerosol direct radiative forcing (e.g., Pilinis et al., 1995), and by promoting secondary aerosol formation it can influence aerosol mass and number that impact both the direct and indirect effect of aerosols (Kanakidou et al., 2005).

Biomass-burning aerosol particles have the potential to act as cloud condensation nuclei (CCN), thereby impacting on cloud properties and climate. Modeling studies suggest that $\mathrm{BB}$ is a significant global source of CCN number (Spracklen et al., 2011). Laboratory and field studies have shown that biomass-burning aerosol is highly hygroscopic and watersoluble, exhibiting up to about half the water uptake capacity of ammonium sulfate (Asa-Awuku et al., 2008; Cerully et al., 2015). Engelhart et al. (2012) found that freshly emitted BBOA displays a broad range of hygroscopicity ( $\kappa$ parameter from 0.06 to 0.6 ) that considerably reduces after just a few hours of photochemical ageing, to a $\kappa$ value of $0.2 \pm 0.1$ (Petters and Kreidenweis, 2007). Few studies, however, focus on the hygroscopicity of ambient BB aerosol as a function of atmospheric age extending out to a few days. Relatively few studies also go beyond CCN to calculations of droplet number (e.g., Roberts et al., 2003), and even fewer studies charac- terize the relative role of aerosol number and chemical composition (hygroscopicity) variability to the predicted droplet number variability in clouds formed from BB-influenced air masses. These issues are important, because the supersaturation that develops in clouds is not known beforehand, nor is it constant, but rather a strong function of the $\mathrm{CCN}$ levels and cloud dynamical forcing (updraft velocity).

In the current study we focus on the hygroscopicity, CCN concentrations and resulting droplet formation characteristics (droplet number and cloud supersaturation) associated with air masses influenced by summertime biomass-burning events in the eastern Mediterranean. The smoke-laden air masses sampled were subject to a range of atmospheric processing (several hours up to three days), identified using remote sensing techniques (Moderate Resolution Imaging Spectroradiometer, Kaufman and Remer, 1994; CloudAerosol Lidar with Orthogonal Polarization, Winker et al., 2009; Mamouri et al., 2012), back-trajectory analysis and other in situ chemical metrics. Values of the hygroscopicity parameter, $\kappa$, were derived from $\mathrm{CCN}$ and Hygroscopic Tandem Differential Mobility Analyzer (HTDMA) measurements and linked to distinct chemical constituents identified with positive matrix factorization of the chemical constituents measured with an Aerosol Chemical Speciation Monitor (ACSM). Finally, the observations are used to predict the cloud droplet number and supersaturation formed in clouds that develop in each air mass, focusing on the contribution of aerosol number and hygroscopicity to the predicted droplet number variability. This is one of the very few field studies that use in situ observations to (i) unravel the contributions of composition and aerosol size to BB-related CCN distributions and their impacts on cloud droplet number and (ii) quantify the contributions of biomass-burning constituents to aerosol hygroscopicity and liquid water in the region.

\section{Experimental methods}

\subsection{Sampling site and period}

The measurements were performed at the Finokalia atmospheric background station $\left(35^{\circ} 32^{\prime} \mathrm{N}, 25^{\circ} 67^{\prime} \mathrm{E}\right.$; http:// finokalia.chemistry.uoc.gr) of the University of Crete, which is part of the Aerosols, Clouds, and Trace gases Research Infrastructure Network (ACTRIS; http://www.actris. net/). More details about the sampling site are provided by Mihalopoulos et al. (1997) and Sciare et al. (2003). Although measurements took place from mid-August to midNovember 2012, the focus of our analysis involves the periods of intense biomass-burning influence from August to September 2012. BB plumes sampled were fresh, originating from the Greek islands and mainland (transport time 6-7 h) but also from long-range transport from the Balkans (transport time $>1$ day) as determined by using Hybrid Single 
Particle Lagrangian Integrated Trajectory Model (HYSPLIT) back-trajectory analysis as shown in detail in Bougiatioti et al. (2014), combined with the hot spots/fire data from Moderate Resolution Imaging Spectroradiometer (MODIS)/Fire Information for Resource Management System (FIRMS; Remy and Kaiser, 2014).

\subsection{Instrumentation and methodology}

Chemical composition and mass concentration of nonrefractory components (ammonium, sulfate, nitrate, chloride and organics) of the submicron aerosol fraction was provided by an Aerodyne Research Aerosol Chemical Speciation Monitor (ACSM; Ng et al., 2011) with a temporal resolution of $30 \mathrm{~min}$. More details of the ACSM measurements and subsequent analysis can be found in Bougiatioti et al. (2014). Total absorption measurements provided the black carbon (BC) concentrations by a seven-wavelength aethalometer (Magee Scientific, AE31). From the BC measurements and using the approach of Sandradewi et al. (2008) the wood burning and fossil fuel contribution to the total BC concentrations were calculated using an absorption exponent of 1.1 for fossil fuel burning and 1.86 for pure wood burning. The aerosol particle-size distributions from 9 to $850 \mathrm{~nm}$ were measured with a 5 min resolution by a custom-built scanning mobility particle sizer (SMPS; TROPOS-type, Wiedensohler et al., 2012) equipped with a condensation particle counter (CPC; TSI model 3772; Stolzenburg and McMurry, 1991). Sample humidity was regulated below the relative humidity of $40 \%$ with the use of Nafion ${ }^{\circledR}$ dryers in both aerosol and sheath flow, and the measured number size distributions were corrected for diffusional particle losses (Kalivitis at al., 2015).

A Continuous Flow Stream-wise Thermal Gradient CCN Chamber (CFSTGC; Roberts and Nenes, 2005) was used in parallel with a Hygroscopic Tandem Differential Mobility Analyzer (HTDMA; Rader and McMurry, 1986) to measure the CCN number, activity and hygroscopicity of ambient aerosol for supersaturated, $(0.1-0.7 \%)$ and subsaturated conditions (relative humidity, $\mathrm{RH}=86 \%$ ), respectively. The whole system, which is illustrated in Fig. 1, sampled air with a total flow rate of $1.8 \mathrm{~L} \mathrm{~min}^{-1}$. After passing through a Nafion dryer (MD-110-12S-2, Perma Pure LLC, RH <30\%) the dried particles were selected based on their electrical mobility by a Differential Mobility Analyzer (DMA-1; TSI Model 3080; Knutson and Whitby, 1975). The sheath flow and classified aerosol outlet flow of DMA-1 were 10.8 and $1.8 \mathrm{~L} \mathrm{~min}^{-1}$, respectively, while the mobility diameter was changed every 6 min between $60,80,100$ and $120 \mathrm{~nm}$.

The classified aerosol from DMA-1 was then split into two streams. The first stream was passed through a Nafion tube humidity exchanger where its RH was increased to $86 \%$. The size distribution of the RH-conditioned particles was determined by a second DMA (DMA-2; custom-made DMA using a closed-loop sheath flow with RH control; Biskos et

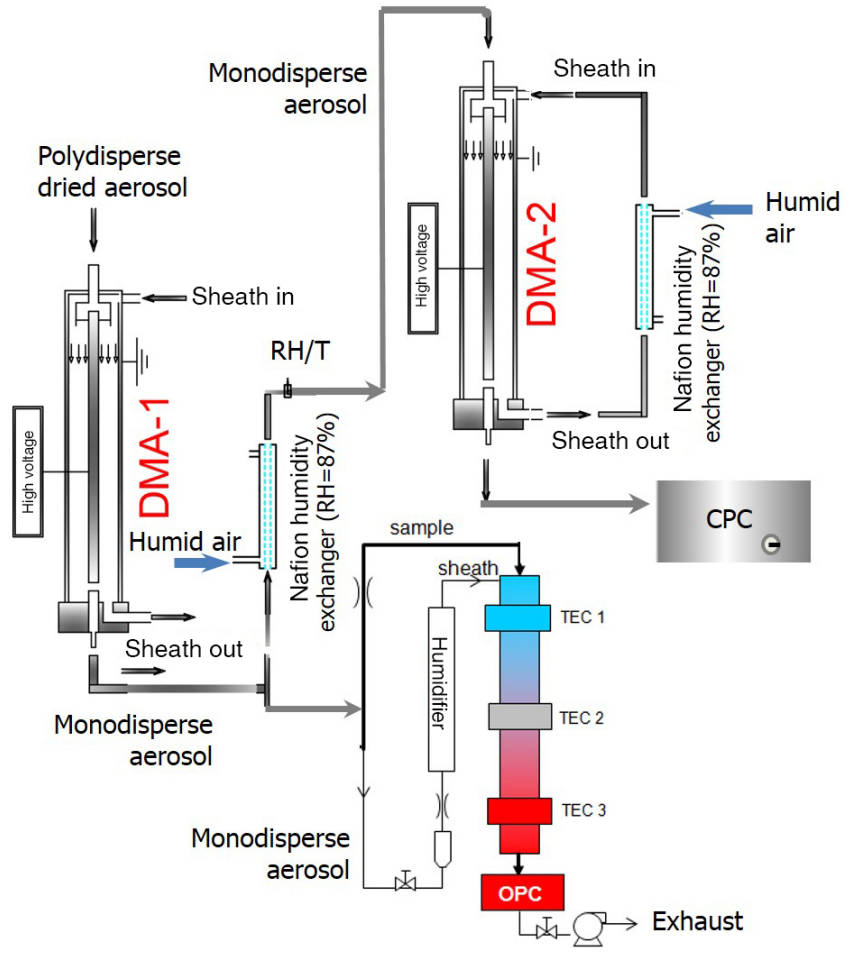

Figure 1. Schematic of the setup used for the $\mathrm{CCN}$ and mixing state measurements.

al., 2006; Bezantakos et al., 2013) coupled with a condensation particle counter (CPC, TSI Model 3772). The RH in both the aerosol and the sheath flow in DMA-2 was controlled by proportional-integral-derivative (PID) controllers to within $\pm 2 \%$ accuracy. Both DMAs in the HTDMA system were calibrated with polystyrene latex (PSL) spheres. The other classified stream was introduced into the CFSTGC to measure the CCN activity of particles. The CFSTGC was operated in scanning flow CCN analysis (SFCA) mode (Moore and Nenes, 2009), in which the flow rate in the growth chamber changes over time, while a constant streamwise temperature difference is applied. This causes supersaturation to change continuously, allowing the rapid and continuous measurement of CCN spectra with high temporal resolution. The SFCA cycle used involved first increasing the flow rate linearly between a minimum flow rate $\left(Q_{\min } \sim 300 \mathrm{~cm}^{3} \mathrm{~min}^{-1}\right)$ and a maximum flow rate $\left(Q_{\max } \sim 1000 \mathrm{~cm}^{3} \mathrm{~min}^{-1}\right)$ over a ramp time of $60 \mathrm{~s}$. The flow was maintained at $Q_{\max }$ for $10 \mathrm{~s}$ and then linearly decreased to $Q_{\min }$ over $60 \mathrm{~s}$. Finally, the flow rate was held constant at $Q_{\min }$ for $10 \mathrm{~s}$ and the scan cycle was repeated. The activated droplets in the CFSTGC were counted and sized at the exit of its growth chamber with an optical particle counter (OPC) that detects droplets and classifies them into 20 size bins with diameter ranging from 0.7 to $10 \mu \mathrm{m}$ every $1 \mathrm{~s}$.

The water vapor supersaturations developed in the CFSTGC during an SFCA cycle were characterized with am- 
monium sulfate calibration aerosol following the procedure of Moore and Nenes (2009). In brief, an ammonium sulfate solution was atomized, dried, charge-neutralized and classified by DMA-1. The resulting monodisperse aerosol flow was split between DMA-2 and the CFSTGC, operating in SFCA mode and with a CFSTGC streamwise temperature difference of $\Delta T=5 \mathrm{~K}$. From this setup, we obtain the instantaneous concentrations of the classified aerosol and the resulting CCN during the SFCA flow cycles. The ratio of $\mathrm{CCN}$ to total aerosol number gives the activation ratio, $R_{\mathrm{a}}$, which varies with the instantaneous volumetric flow rate, $Q$, in the CFSTGC. Using data from multiple SFCA flow cycles, $R_{\mathrm{a}}$ is then fit to a sigmoid function that depends on $Q$ :

$R_{\mathrm{a}} \equiv \frac{\mathrm{CCN}}{\mathrm{CN}}=a_{o}+\frac{a_{1}-a_{0}}{1+\left(Q / Q_{50}\right)^{-a_{2}}}$,

where $a_{0}, a_{1}, a_{2}$ and $Q_{50}$ are constants which describe the minimum, maximum, slope and inflection point of the sigmoidal, respectively. The "critical flow rate", $Q_{50}$, corresponds to the instantaneous flow rate that produces a level of supersaturation, $s$, required to activate the measured monodisperse aerosol and determined from the size of the classified aerosol using Köhler theory (Moore et al., 2012a).

Repeating the procedure for many sizes of classified ammonium sulfate results in the SFCA calibration curve, which gives the supersaturation in the CFSTGC as a function of flow rate (i.e $Q_{50}$ vs. $s$ ) throughout an SFCA flow cycle. Absolute uncertainty of the calibrated CCNC supersaturation is estimated to be $\pm 0.04 \%$ (Moore et al., 2012a, b).

In our instrument setup, $R_{\mathrm{a}}$ can change either from variations in the size of the monodisperse aerosol, $d_{\mathrm{p}}$, or the instrument supersaturation, $s$ (or flow rate, $Q$ ). The independently varied parameter is indicated hereafter in parentheses in front of the activation ratio, e.g., $R_{\mathrm{a}}(Q), R_{\mathrm{a}}(s), R_{\mathrm{a}}\left(d_{\mathrm{p}}\right)$ for $R_{\mathrm{a}}$ as a function of $Q, s$ and $d_{\mathrm{p}}$, respectively.

Analysis of $R_{\mathrm{a}}$ obtained for our experimental setup for ambient particles samples provides very important information on the activity and chemical mixing state of the CCN. This is carried out as follows. For every particle size $d_{\mathrm{p}}$ set by the DMA-1, $R_{\mathrm{a}}(Q)$, is measured at every instant in the CFSTGC according to Eq. (1). Typically $a_{0} \ll a_{1}$; given that $Q$ and $s$ are related through the calibration, $R_{\mathrm{a}}(Q)$ data can be transformed to $R_{\mathrm{a}}(s)$ :

$R_{\mathrm{a}}(s)=\frac{E}{1+\left(\frac{s}{s^{*}}\right)^{C}}$,

where $s, s^{*}$ correspond to $Q, Q_{50}$ of the monodisperse aerosol. $E$ and $C$ are parameters determined from fitting. According to Cerully et al. (2011), $R_{\mathrm{a}}(s)$ represents a cumulative distribution of critical supersaturation for particles with dry diameter $d_{\mathrm{p}}$; Köhler theory can then be applied to express $R_{\mathrm{a}}(s)$ in terms of the hygroscopicity parameter $R_{\mathrm{a}}(\kappa)$ :

$R_{\mathrm{a}}(\kappa)=\frac{E}{1+\left(\frac{\kappa}{\kappa^{*}}\right)^{C / 2}}$, where $\kappa=\frac{4 \mathrm{~A}^{3}}{27 d_{\mathrm{p}}^{3} s^{2}}$ expresses the dependence of $\kappa$ on $d_{\mathrm{p}}$ and $s, A=\frac{4 M_{\mathrm{w}} \sigma_{\mathrm{w}}}{R T \rho_{\mathrm{w}}}$ is the Kelvin parameter, while $M_{\mathrm{w}}, \sigma_{\mathrm{w}}$ and $\rho_{\mathrm{W}}$ are, respectively, the molar mass, the surface tension and the density of water. $R$ is the universal gas constant and $T$ is temperature.

In Eqs. (2), (3), $s^{*}$ and $\kappa *$ correspond to the characteristic critical supersaturation and hygroscopicity parameter of the monodisperse aerosol, respectively, and correspond to the most probable value of the parameters (Cerully et al., 2011). From Eq. (3), the probability distribution function for $\kappa, p^{s}(\kappa)$, can be derived for the ambient monodisperse aerosol (Cerully et al., 2011):

$p^{s}(\kappa)=\frac{1}{E} \frac{d R_{\mathrm{a}}(\kappa)}{\mathrm{d} \kappa}=-\frac{\frac{C}{\kappa^{* 2}}\left(\frac{\kappa}{\kappa^{*}}\right)^{\frac{C}{2}-1}}{\left(1+\left(\frac{\kappa}{\kappa^{*}}\right)^{\frac{C}{2}}\right)^{2}}$.

Analysis of $p^{s}(\kappa)$ can provide a direct measure of the chemical heterogeneity of the $\mathrm{CCN}$ population. For this, we adopt the metric of chemical dispersion, $\sigma(\kappa)$, introduced by Lance (2007) and further developed in Cerully et al. (2011) and Lance et al. (2013):

$\sigma^{2}(\kappa)=\frac{\int_{0}^{1}\left(\kappa-\kappa^{*}\right)^{2} p^{s}(\kappa) \mathrm{d} \kappa}{\int_{0}^{1} p^{s}(\kappa) \mathrm{d} \kappa}$,

where $\sigma(\kappa)$ is the square root of variance of $\kappa *$; as the chemical heterogeneity of the $\mathrm{CCN}$ increases, the distribution of $\kappa$ broadens, and $\sigma(\kappa)$ becomes larger so that the range in $\mathrm{CCN}$ hygroscopicity is given by $\kappa^{*} \pm \sigma(\kappa)$.

Particle water uptake at subsaturated conditions in the Nafion tube humidity exchanger and DMA-2 was also evaluated by the growth factor measured for the calibration $\left(\mathrm{NH}_{4}\right)_{2} \mathrm{SO}_{4}$. Particle hygroscopic growth at subsaturated conditions $\left(g_{i}\right)$ is obtained:

$g(\mathrm{RH})=\frac{d_{\mathrm{m}}(\mathrm{RH})}{d_{\mathrm{p}}}$,

where $d_{\mathrm{m}}(\mathrm{RH})$ and $d_{\mathrm{p}}$ are the geometric mean mobility diameters of the sampled particles at the hydrated state (i.e., at $\mathrm{RH}=86 \%$ ) as measured by DMA-2 and the CPC, and at the dry state selected by DMA-1 $(\mathrm{RH}<30 \%)$. Particle-size distributions at $86 \% \mathrm{RH}$ were inverted using the TDMA fit algorithm (Stolzenburg and McMurry, 1988), which is also capable of distinguishing between internally and externally mixed aerosols (e.g., Bezantakos et al., 2013).

Hygroscopicities determined from the $\mathrm{CCN}$ measurements are differentiated by corresponding values from the HTDMA measurements by adding a subscript CCN or HTDMA (e.g., $\left.\kappa_{\mathrm{HTDMA}}, \kappa_{\mathrm{CCN}}\right) \kappa_{\mathrm{HTDMA}}$ is calculated from the HTDMA- 
measured subsaturated hygroscopic growth factors:

$\kappa_{\mathrm{HTDMA}}=\left(g(\mathrm{RH})^{3}-1\right)\left(\frac{\exp \left(\frac{A}{g(\mathrm{RH}) \cdot d_{\mathrm{p}}}\right)}{\frac{\mathrm{RH}}{100 \%}}-1\right)$,

with $A$ being the Kelvin parameter defined in Eq. (3). The exponential term of this equation (i.e., the Kelvin term) is used to account for curvature effects on vapor pressure.

An average value of the hygroscopic parameter at each dry particle size, $d_{\mathrm{p}}$, which is representative of the hygroscopic properties of the entire particle population, is obtained as follows:

$\overline{\kappa_{\mathrm{HTDMA}}}=\int_{g_{\min }}^{g_{\max }} \kappa\left(g_{(\mathrm{RH})}\right) p\left(g_{(\mathrm{RH})}\right) \mathrm{d} g_{(\mathrm{RH})}$,

where $\kappa\left(g_{(\mathrm{RH})}\right)$ is obtained from the growth-factor probability distribution using Eq. (5) and $p\left(g_{(\mathrm{RH})}\right)$ is the probability of each growth factor. $g_{\min }, g_{\max }$ are the minimum and maximum growth factors obtained from the growth-factor probability distribution and represent the minimum and maximum $g$ with non-zero probability value.

To support the in situ instruments, we used space-borne laser remote sensing (lidar) data from the Cloud-Aerosol Lidar with Orthogonal Polarization (CALIOP) (Mamouri et al., 2009; Winker et al., 2009) to characterize the plumes emerging from the fire hot spots. The fire plume originating from any location can be tracked by HYSPLIT back-trajectory analysis (Bougiatioti et al., 2014), and lidar observations can be used to check the presence of aerosol layers and aerosol types. Optical confirmation of the smoke plumes is provided by MODIS and FIRMS as shown in the supplementary material of Bougiatioti et al. (2014).

\section{Results and discussion}

\subsection{Identifying periods of biomass-burning influence}

Bougiatioti et al. (2014) identified the BB events analyzed here by the time evolution of absorption enhancements (BC) in the aerosol, which was further verified by FIRMS and back-trajectory analysis. During these events mass spectrometric biomass-burning tracers (i.e., fragments $m / z=60$ and 73) also exhibited elevated levels. Clear biomass-burning contribution was identified by source apportionment using positive matrix factorization (PMF) analysis for four distinct events. The BB events considered include a severe fire event that burned most of the island of Chios (19-21 August), an extensive wildfire at the Dalmatian coast in Croatia resulting in smoke plumes that spread across the Balkans during the period 28-30 August, and less extensive fires on the Greek islands of Euboea (3-5 September) and Andros (12-13 September). All fire events exhibited discrete BBOA profiles depending on the biomass-burning fuel, as presented in detail by Bougiatioti et al. (2014). Nevertheless, the organic aerosol derived from the ageing of the biomass-burning aerosol (OOA-BB) identified for all events had a similar profile, regardless of the BBOA it was derived from (Bougiatioti et al., 2014). A transport time estimate and back-trajectory analysis were conducted with the plume arrival (h) from base time graphics with the help of the HYSPLIT model (http://www.arl.noaa.gov/HYSPLIT_info.php).

MODIS and CALIOP measurements confirm the validity of the Bougiatioti et al. (2014) analysis by clearly showing the origin, transport path and characteristics of the biomassburning plume from the Chios fire on 18 and 19 August 2012. Indeed, in Fig. 2a we show the MODIS true color image showing the plume emerging from the Chios fires on $18 \mathrm{Au}-$ gust 2012 as obtained during its 09:39 UTC overpass over Greece (Kyzirakos et al., 2014). The blue and red lines delineate the ground track of the CALIPSO satellite during its overpass over Crete several hours later on 19 August 2012 (the first between 00:27 and 00:40 and the second between 11:34 and 11:47 UTC); the red star shows the sampling site at Finokalia station. The CALIPSO vertical profiles of the aerosol backscatter coefficient (in $\mathrm{km}^{-1} \mathrm{sr}^{-1}$ ) at 532 and $1064 \mathrm{~nm}$ for the two overpasses are shown in Fig. 2b (lefthand side) together with the corresponding linear particle depolarization ratio at $532 \mathrm{~nm}$ obtained between 00:27:30 and 00:40 UTC (right-hand side). Comparing the midnight and the daytime aerosol backscatter profiles in Fig. 2b, we observe that the midnight values are 3-4 times lower than the daytime ones for altitudes up to $3 \mathrm{~km}$ height. In addition, the daytime observations show a discrete aerosol layer below $1.5 \mathrm{~km}$. As for the linear particle depolarization ratio it shows a mean value of $19 \%$ up to $1.25 \mathrm{~km}$ height and less than $6-10 \%$ above $(1.25-2 \mathrm{~km})$.

Finally, we made use of the classification scheme of the CALIPSO data (Omar et al., 2009) to classify the different subtypes of aerosols in the plume captured during its first overpass over Crete on 19 August 2012 (00:27-00:40 UTC). This classification scheme, based on the optical and microphysical properties of the sampled aerosols indeed reveals the presence of a mixture of smoke, polluted dust and marine particles observed below a $3 \mathrm{~km}$ altitude (black color for smoke, brown for polluted dust and blue for marine) as shown in Fig. 2c, within the depicted area between $39^{\circ} \mathrm{N}$, $24.1^{\circ} \mathrm{E}-37^{\circ} \mathrm{N}, 23.4^{\circ} \mathrm{E}$, just NW of the Finokalia station and along the CALIPSO ground track. According to this classification, over Crete the presence of polluted dust (mixed with smoke and marine aerosols) prevails within the marine boundary layer, which for Finokalia is approximately $1 \mathrm{~km}$ (Kalivitis et al., 2007), extending up to $0.8-1.2 \mathrm{~km}$ height. This implies that for the 00:27-00:40 UTC time slot, the $\mathrm{BB}$ aerosols sampled by the ground-based in situ measurements at Finokalia would contribute less (due to dilution) to the global aerosol mass loading than if measured over western Crete. 
(a)

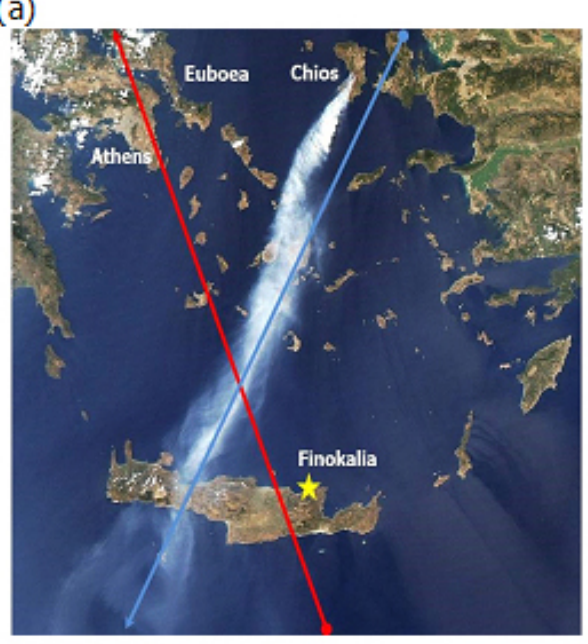

(b)

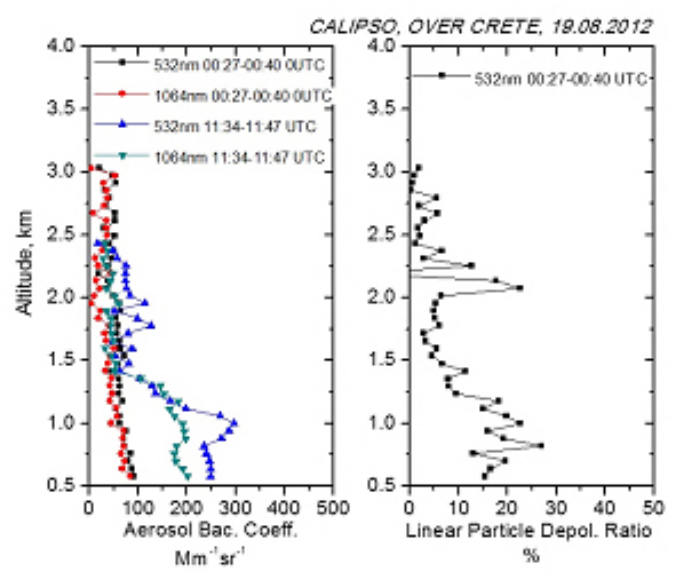

Aerosol Subtype UTC: 2012-08-19 00:27:30.3

to $2012-08-1900: 40: 59.0$

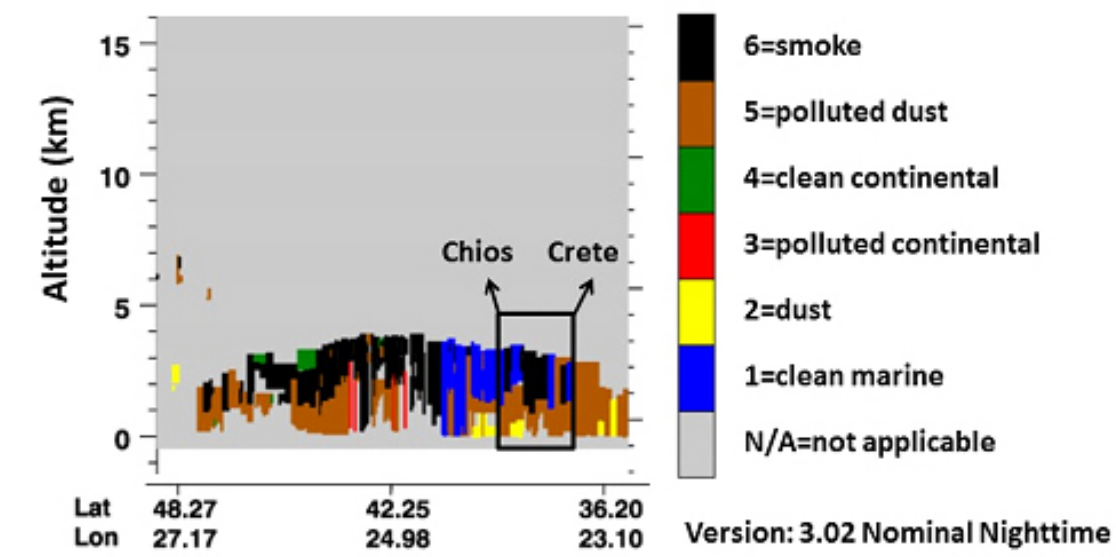

(c)

Figure 2. (a) Satellite composite view from MODIS of the fire plume emerging from the island of Chios on 18 August 2012 (courtesy of NASA). The blue and red lines delineate the two ground tracks of the CALIPSO satellite during its overpass over Crete on 19 August 2012 between 00:27-00:40 and 11:34-11:47 UTC. (b) Vertical profiles of the aerosol backscatter coefficient (in $\mathrm{km}^{-1} \mathrm{sr}^{-1}$ ) at 532 and $1064 \mathrm{~nm}$ (left) and linear particle depolarization ratio at $532 \mathrm{~nm}$ (right) measured by CALIPSO and (c) vertical profiles of the aerosol subtypes captured by CALIPSO during its overpass over Crete; the marked area is located at the NW of Finokalia station (00:27-00:40 UTC).

\section{2 $\mathrm{PM}_{1}$ composition}

The average mass concentration for the whole measurement period (mid-August to mid-November 2012), based on the ACSM measurements combined with BC from the aethalometer, was $9.2 \pm 4.8 \mu \mathrm{g} \mathrm{m}^{-3}$. The corresponding median concentrations for the main aerosol constituents were $3.56,1.31,3.03$ and $0.47 \mu \mathrm{g} \mathrm{m}^{-3}$ for sulfate, ammonium, organics and $\mathrm{BC}$, respectively. Figure 3 represents the time series of the major submicron species where it can be seen that during the fire events the contribution of organics and BC increased substantially (from 34.9 to $46.5 \%$ for organics and from 6.1 to $9.5 \%$ for BC) with a simultaneous reduction of that of sulfate. Source apportionment clearly shows that these increases are related to BB influences (Bougiatioti et al., 2014). During all BB events there is a clear dominance of wood burning over fossil fuel contributions to BC. The wood burning component of $\mathrm{BC}$ is also provided as a reference, depicting the enhanced contribution of biomass burning during the highlighted events.

Based on the size-resolved $\mathrm{CCN}$ activity measurements and the inferred hygroscopicity parameter $\kappa$ of the aerosol (Eq. 3), it is evident that the changes in the organics and sulfate mass fractions will also influence the $\mathrm{CCN}$ concentrations, activation fractions and hygroscopicity. As the ACSM provides bulk submicron chemical composition and thus is 


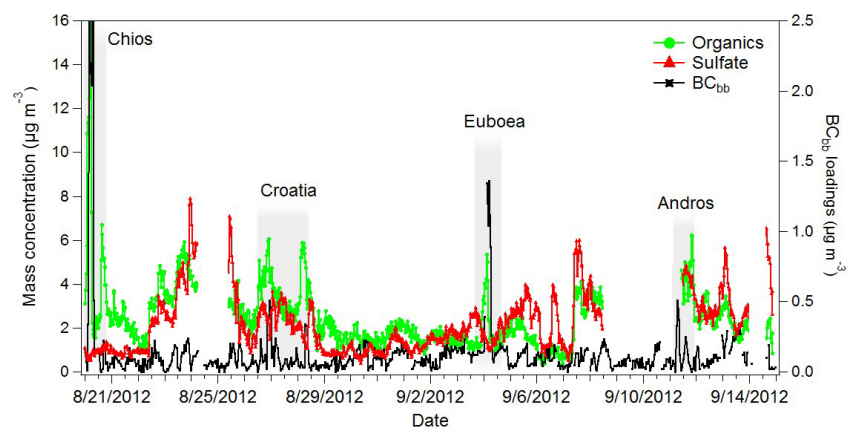

Figure 3. Time series concentrations of major $\mathrm{PM}_{1}$ species that contribute in the identification of the BB events. The shaded areas represent the four considered fire events.

not able to capture any size-dependent chemical composition, the size-resolved $\mathrm{CCN}$ activity measurements are able to resolve distinct $\mathrm{CCN}$ activity and mixing state of the different particle sizes. These aspects are thoroughly investigated in the following sections.

\section{3 $\mathrm{CN}$ and $\mathrm{CCN}$ number concentrations and biomass-burning events}

For all four events of biomass-burning-influenced air masses arriving at Finokalia, the observed aerosol number concentration increased considerably, regardless of size. The increases are quantitatively expressed using averaged data from at least $6 \mathrm{~h}$ prior to the arrival time of the BB smoke. For particle sizes above $100 \mathrm{~nm}, \mathrm{BB}$ increased concentrations by $65 \%$ for the Chios fire, around $50 \%$ for the Croatia fire, $88 \%$ for the Euboea fire and about $150 \%$ for the Andros fire. Less pronounced increases were seen for the smaller particle sizes. The corresponding impacts on CCN concentrations for the classified aerosol are shown in Fig. 4 for all fire events. Concentrations are given at the characteristic supersaturation, $s *$, of the monodisperse $\mathrm{CCN}$ as classified by DMA-1 (Sect. 2.2). Within each event, $s *$ did not vary by more than $13.6 \%$; therefore most of the variability in $\mathrm{CCN}$ number can be attributed to variations in the size distribution, rather than shifts in the chemical composition (i.e., $s *$ ).

As expected, smaller particles exhibit a higher critical supersaturation (Bougiatioti et al., 2011). During periods with smoke influence, critical supersaturations tend to increase, indicating that particles associated with $\mathrm{BB}$ are less effective $\mathrm{CCN}$ compared to those of the background aerosol. To quantify the direct influence of biomass burning to particle and $\mathrm{CCN}$ number concentrations, we studied the concentration of the BBOA component, identified by PMF analysis of the ACSM mass spectra (Bougiatioti et al., 2014). The BBOA concentration time series depicts the arrival time of the smoke and the intensity of the BB influence.

The data shown in Fig. 4 indicate that during the majority of the identified biomass-burning events, $\mathrm{CCN}$ concen- trations for the larger particles sizes increase and follow the BBOA trend. This increase was more pronounced, depending on the proximity of the fire and therefore the travel time of the air masses. Rose et al. (2010) also observed increases in $\mathrm{CCN}$ during a biomass-burning event near the megacity Guangzhou, China, where $\mathrm{CCN}$ number concentrations at $s=0.068$ and $0.27 \%$, increased by 90 and $8 \%$, respectively. The same study attributed these changes to increases in the particle size when BB influence was present.

Of all particle sizes examined, it appears that those having mobility diameter of $60 \mathrm{~nm}$ exhibit the least variability in terms of $\mathrm{CCN}$ number concentration before and during the BB influence (Fig. 4, open circles). The concentration, however, significantly increased during the BB event from Croatia (Fig. 4b). This event, together with others of smaller extent, is associated with new particle formation (NFP) events. The observed frequency of NPF days at Finokalia is close to $30 \%$ (Kalivitis et al., 2015), regardless of the presence or not of BB-laden air masses. Based on aerosol chemical composition, it appears that both gaseous sulfuric acid and organic compounds take part in the growth of nucleated particles to CCN-relevant sizes. These organic compounds that contribute to the nuclei growth may be of different origins, including biogenic emissions, biomass burning and other possible anthropogenic sources from long-range transport (Kalivitis et al., 2015). From Fig. 4b it appears that when the BB event is combined with such a NPF event within a few hours, $60 \mathrm{~nm}$ particles are strongly influenced and their $\mathrm{CCN}$ concentrations increase considerably. The influence on BB to the hygroscopicity of $60 \mathrm{~nm}$ particles and the other sizes is examined in a subsequent section. A detailed discussion on these events and their contribution to CCN concentrations is provided by Kalivitis et al. (2015).

\section{4 $\mathrm{CCN}$ activation fractions during fire events}

As demonstrated in the preceding section, $\mathrm{CCN}$ number concentrations during the biomass-burning events proportionately increased for the larger particle sizes. Figure 5 shows the activation fractions $\left(R_{\mathrm{a}}(Q)\right)$ for three of the four particle sizes and the four considered fire events $(120 \mathrm{~nm}$ is not shown as it exhibits the same behavior as $100 \mathrm{~nm}$ ). As an indicator of $\mathrm{BB}$ influence, we use the concentration of the aged BB factor identified in the ACSM spectra (OOA-BB), as it represents the atmospherically processed component of $\mathrm{BBOA}$. This factor is chosen as it constitutes a larger part of the organic aerosol (30\%) with BB influence and its ageing is expected to be reflected in terms of CCN activity.

For all particle sizes, the activation fractions are derived from the asymptote of the fitting to the sigmoidal function of the $R_{\mathrm{a}}(s)$ during each supersaturation cycle and represents the $\mathrm{CCN}$ behavior at the highest supersaturations measured $(s>0.6 \%)$. Figure 5 shows that even though CCN concentrations increase for particles larger than $80 \mathrm{~nm}$, their activation fractions remain more or less stable and very close to 
(a)
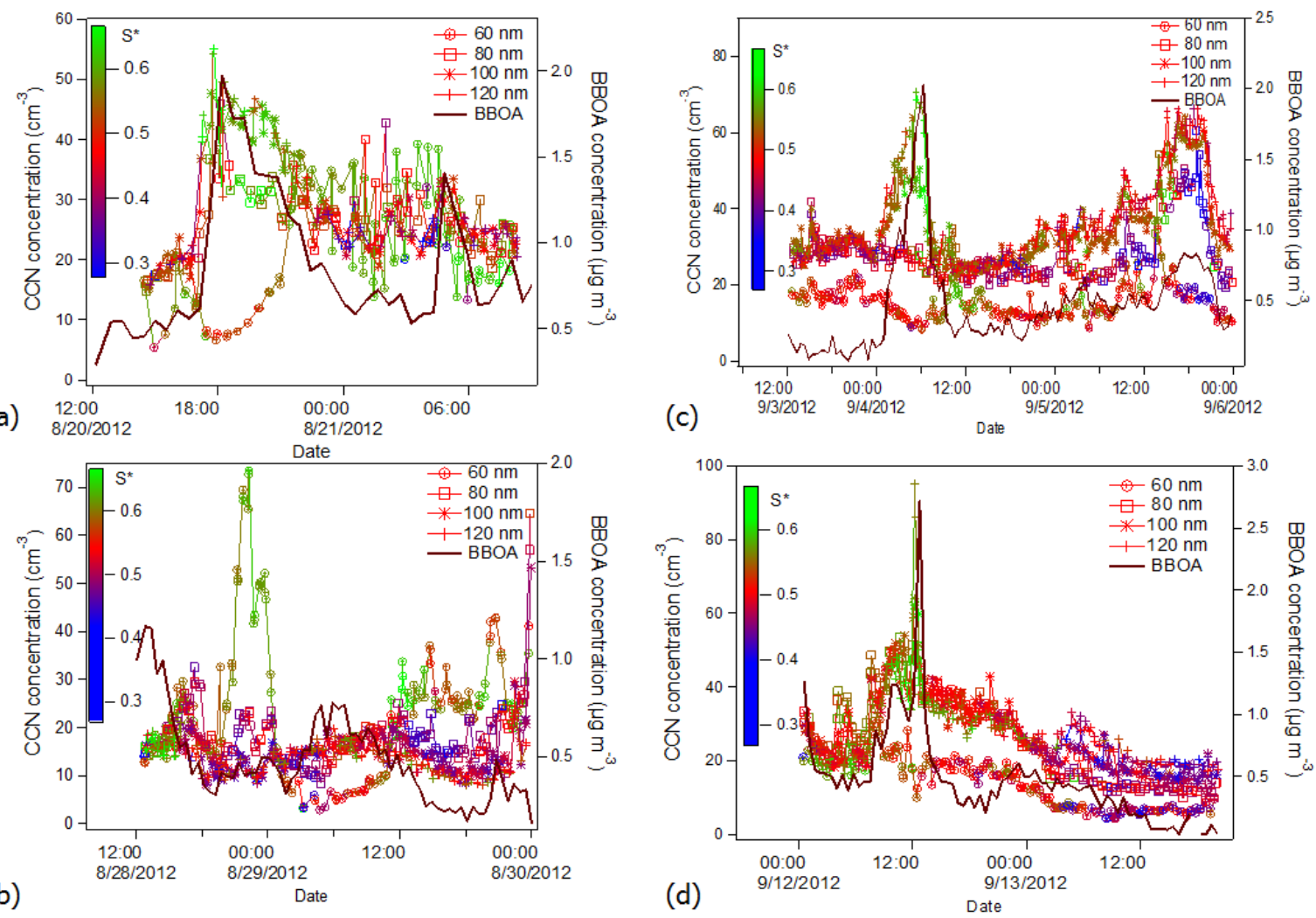

Figure 4. CCN concentrations for the selected particle sizes during the arrival of the smoke plumes for (a) Chios, (b) Croatia, (c) Euboea and (d) Andros. The black solid line represents the biomass-burning component of the organic aerosol at the given time.

unity throughout the events. This observation implies that almost all aerosol particles larger than $80 \mathrm{~nm}$ are $\mathrm{CCN}$ active at supersaturations higher than $0.6 \%$, within uncertainties. This is not the case for $60 \mathrm{~nm}$ particles which have activation fractions at $0.6 \% s$ (and in the case of the Chios fire activation fractions of $80 \mathrm{~nm}$ particles as well at $0.4 \% s$ ) exhibit the highest variability, with ratios approaching values as low as $40 \%$. It can be seen that as concentrations of the OOA-BB start to increase, the activation fractions of $60 \mathrm{~nm}$ particles at $\sim 0.6 \% s$ start to diminish. It thus appears that larger particles are mostly internally mixed, as also seen by their high activation ratios, while small particles could be externally mixed populations. An indication of the heterogeneity of the smaller particle sizes compared to the larger ones is the slope of the sigmoid fit to the $R_{\mathrm{a}}(s)$; the steeper the slope, the more homogeneous the population, and given that the $60 \mathrm{~nm}$ particles exhibited the broader slopes, the more heterogeneous these particles are. This can be explained by a size-dependent chemical composition and the presence of a population with notable lower hygroscopicity that prohibits the particles from acting as $\mathrm{CCN}$ and can be attributed to different sources and atmospheric processing (coagulation, cloud processing and condensation of secondary aerosol) that generally tend to internally mix the particles, rendering them more $\mathrm{CCN}$ active. Indeed, the lowest activation fractions occur for the strongest events where the time for transport and ageing is most limited (hence least aged and hygroscopic). The particle chemical dispersion retrievals (Sect. 3.5) also support this view. The same conclusion is also drawn from the data provided by Bougiatioti et al. (2011) for the same sampling site during summertime, and are verified by analysis of the chemical dispersion and HTDMA data shown in following sections. The evolution of the mixing state of each particle size is further investigated by the HTDMA measurements in a subsequent section (Sect. 3.6) as well.

\subsection{Hygroscopicity and chemical heterogeneity during the biomass-burning events}

The characteristic hygroscopicity parameters, $\kappa *$, derived from the CCN measurements for all particle sizes and for the four selected fire events are presented in Fig. 6. As a reference for the arrival time and magnitude of the event, the concentration of the BBOA factor is also shown in the figure, which has the characteristics of the freshly emitted $\mathrm{BB}$ aerosol and is expected to have more influence on the hygroscopicity of the particles. The smaller particles have the lowest $\kappa_{\mathrm{CCN}}$ values, and hygroscopicity consistently increased with size. This hygroscopicity trend has also been observed elsewhere (Dusek et al., 2010; Cerully et al., 2011; Levin et 

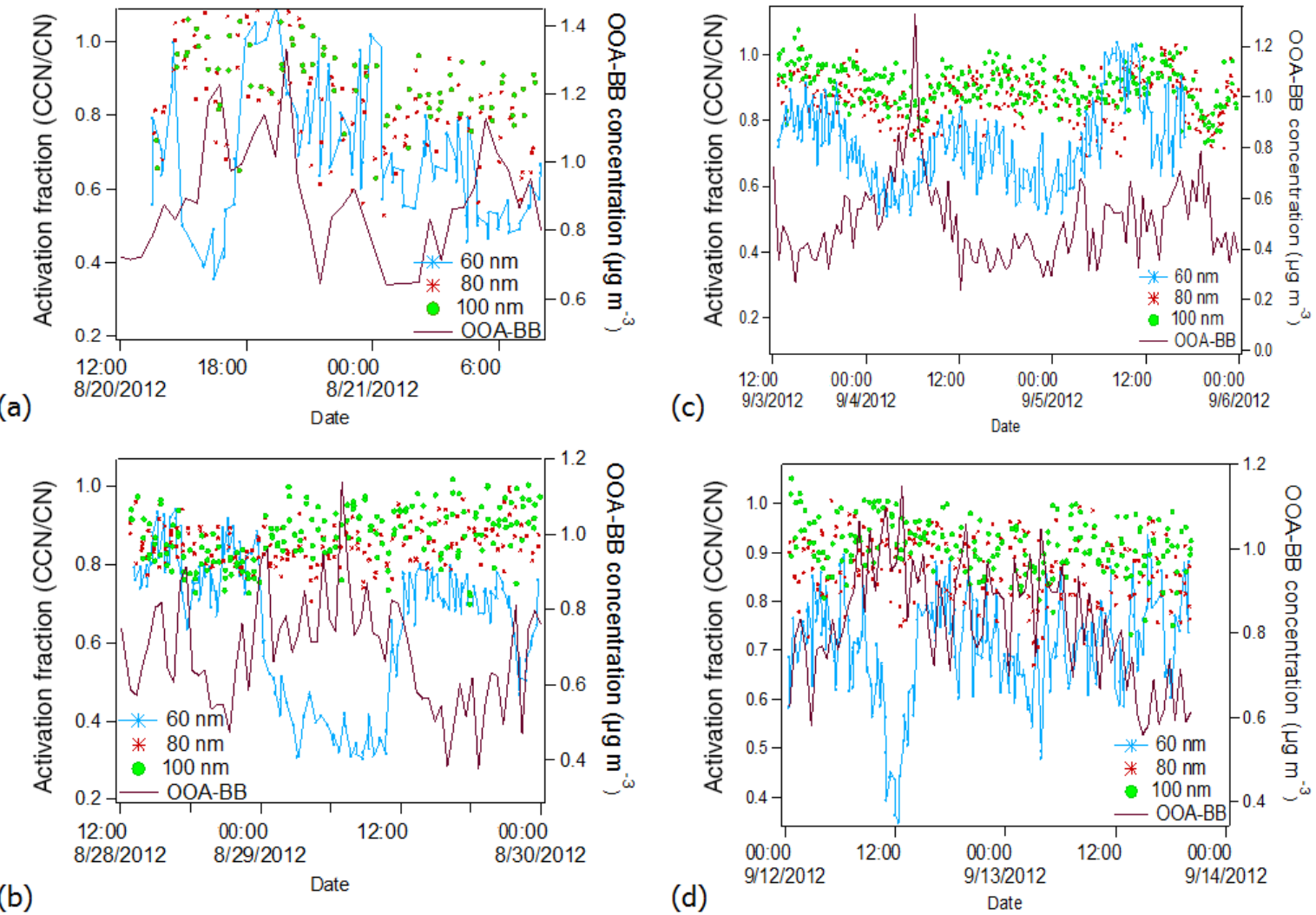

Figure 5. Activation fractions for the selected particle sizes during the arrival of the smoke plumes for (a) Chios, (b) Croatia, (c) Euboea and (d) Andros. The brown solid line represents the processed biomass-burning component of the organic aerosol.

al., 2012; Paramonov et al., 2013; Liu et al., 2014) and is attributed to the enrichment in organic material of sub- $100 \mathrm{~nm}$ particles. Based on the derived $\kappa$ values for each particle size and with knowledge of the distinct species identified by the ACSM (organics, sulfate) and their respective hygroscopicities, the volume fractions for organics and inorganics (mainly ammonium sulfate) were estimated for each particle size. It indeed occurs that $60 \mathrm{~nm}$ particles are on average $89 \%$ composed of organics, while the respective values for 80,100 and $120 \mathrm{~nm}$ particles are 70, 50 and $41 \%$. Most of the accumulation mode particles result from condensation of secondary sulfates, nitrates and organics from the gas phase and coagulation of smaller particles (Seinfeld and Pandis, 2006). In order to examine the contribution of constituents from primary sources that are not measured by the ACSM to the accumulation mode particles, we compared the mass derived from the $\mathrm{ACSM}+\mathrm{BC}$ and the integrated volume distribution from the SMPS converted to mass. During the examined fire events, the ACSM+BC was on average $68.6 \pm 19.3 \%$ of the SMPS-derived mass. Therefore this is an indication that nonrefractory material neglected by the ACSM in the accumulation mode particles probably has a small influence on particle hygroscopicity. Accumulation mode particles can also result from cloud processing. Based on cloud droplet calculations presented in a subsequent section (Sect. 3.8) it appears that particles subject to atmospheric processing would be present in a separate mode around $120 \mathrm{~nm}\left(s_{\max } \sim 0.08 \%\right)$. Particles larger than $100 \mathrm{~nm}$ are usually more aged than the smaller particles and more immediately associated with BB plumes and the atmospheric processing they undergo (Kalivitis et al., 2015). The hygroscopicity parameter for 100 and $120 \mathrm{~nm}$ particles are very similar and the fact that the variability in the respective chemical composition is limited may indeed be attributed to cloud processing, while $80 \mathrm{~nm}$ particles are in between the lowest and highest $\kappa_{\mathrm{CCN}}$ values, an indication of size-dependent chemical composition of components with different hygroscopicities.

Figure 6 also shows that during the arrival of the biomassburning-laden air masses, $\kappa$ values of all particle sizes range within $0.2-0.3$. This observation is consistent with values observed from chamber experiments of fresh and aged biomassburning aerosol and in situ studies from the field. Engelhart et al. (2012) performed a study where 12 different biomass fuels commonly burnt in North American wildfires were used to characterize their respective hygroscopicity. They found that while $\kappa$ of freshly emitted BBOA prior to photochemical ageing covered a range from 0.06 to 0.6 , after a few hours of photochemical processing, the variability of biomass-burning $\kappa$ values from the different fuels was reduced and hygroscopicity converged to a value of $0.2 \pm 0.1$ 
(a)

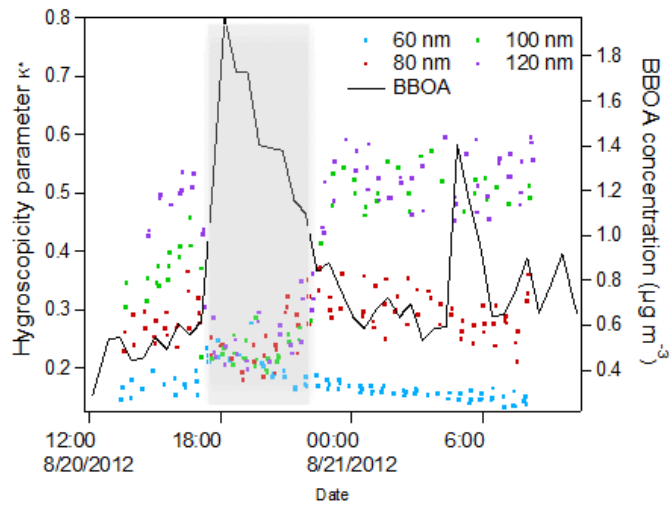

(b)

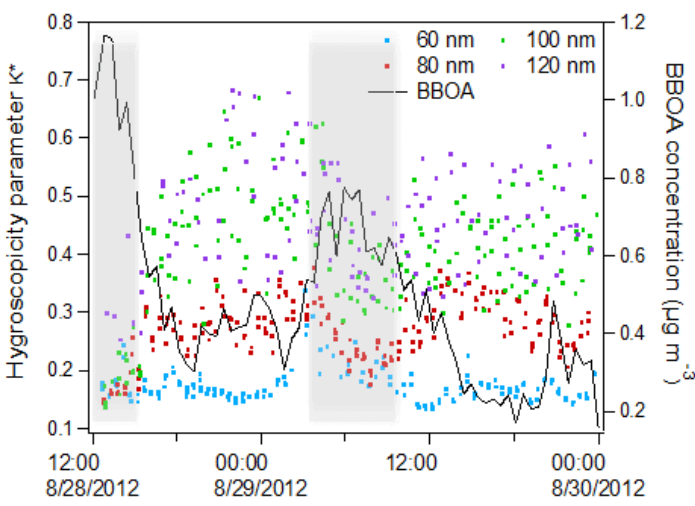

(c)

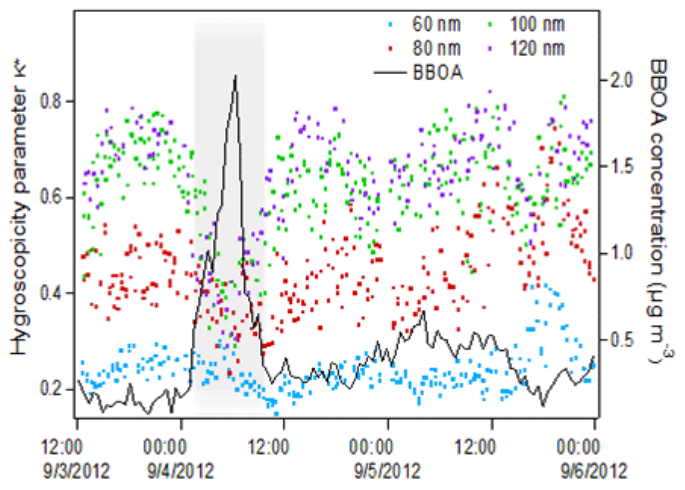

Date

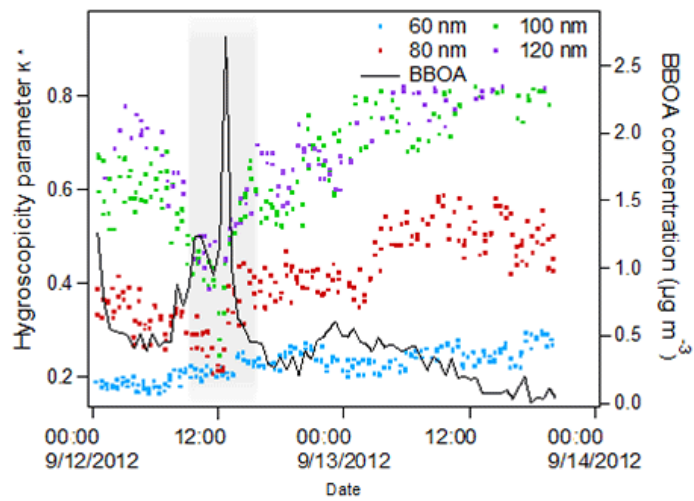

(d)

Figure 6. Characteristic hygroscopicity parameters of the selected particle sizes for (a) Chios, (b) Croatia, (c) Euboea and (d) Andros. The solid line represents the biomass-burning component of the organic aerosol at the given time and the shaded areas represent the smoke plume influence period.

(Cerully et al., 2011; Engelhart et al., 2012). Based on the derived hygroscopicity parameters for each particles size before and during the BB influence, it occurs that smoke causes a relative decrease of $\kappa$ in the order of $22 \%$ for $80 \mathrm{~nm}$ particles, $30.6 \%$ for $100 \mathrm{~nm}$ particles and $30.9 \%$ for $120 \mathrm{~nm}$ particles on average for the four events, while $\kappa$ for $60 \mathrm{~nm}$ particles deviate by only $14 \%$.

During the fire events the contribution of organics and $\mathrm{BC}$ to the submicron aerosol mass fraction increased significantly while the presence of sulfate declined. This is expected to influence the $\mathrm{CCN}$ activity of the sampled aerosol particles as it would cause variations in the inorganic and organic mass fractions. It has already been established that the $\kappa$ value of primary aerosol decreases as the organic mass fraction of aerosol increases (Petters et al., 2009; Engelhart et al., 2012). With photochemical ageing, the increased oxygenation of the freshly emitted BBOA may influence the hygroscopicity of the organic components, but the concurrent increase of the inorganic fraction of the aerosol contributes to the observed increase of $\kappa_{\mathrm{CCN}}$ (inorganic content vs. ageing).

To examine the impact of atmospheric processing and ageing on the composition of the sampled aerosol, we studied
Table 1. Calculated chemical dispersion in terms of $\sigma(\kappa) / \kappa$ for the four studied fire events and all measured particle sizes.

\begin{tabular}{lcccc}
\hline & $60 \mathrm{~nm}$ & $80 \mathrm{~nm}$ & $100 \mathrm{~nm}$ & $120 \mathrm{~nm}$ \\
\hline Chios & $0.85 \pm 0.14$ & $0.73 \pm 0.14$ & $0.60 \pm 0.20$ & $0.41 \pm 0.16$ \\
Croatia & $0.77 \pm 0.18$ & $0.68 \pm 0.19$ & $0.44 \pm 0.12$ & $0.41 \pm 0.10$ \\
Euboea & $0.70 \pm 0.20$ & $0.49 \pm 0.10$ & $0.32 \pm 0.08$ & $0.29 \pm 0.06$ \\
Andros & $0.71 \pm 0.10$ & $0.52 \pm 0.13$ & $0.34 \pm 0.10$ & $0.30 \pm 0.06$ \\
\hline
\end{tabular}

the chemical dispersion $\sigma(\kappa)$ of the hygroscopicity parameter $\kappa$, expressed by the standard deviation of kappa around the most probable hygroscopicity $\kappa *$, and its dependence on particle size. As normal operation uncertainties and the DMA transfer function can induce a broadening of $R_{\mathrm{a}}(s)$ and $R_{\mathrm{a}}(\kappa)$ and therefore contribute to $\sigma(\kappa)$, the inferred $\sigma(\kappa)$ contains a fairly constant instrument offset and a time-dependent constituent that is representative of the real chemical variability. This offset value, owing to the DMA transfer function and other instrument limits has been calculated to be roughly 0.25 (Cerully et al., 2011). Table 1 shows the calculated chemical dispersion, in terms of $\sigma(\kappa) / \kappa$, for the four fire events and the measured particle sizes. It is immediately apparent that 
Table 2. Average CFSTGC-derived $\kappa_{\mathrm{CCN}}$ values and HTDMAderived $\kappa_{\text {HTDMA }}$ values for the selected particles sizes.

\begin{tabular}{lcc}
\hline & $\kappa_{\text {HTDMA }}$ & $\kappa_{\mathrm{CCN}}$ \\
\hline $60 \mathrm{~nm}$ & $0.23 \pm 0.07$ & $0.22 \pm 0.05$ \\
$80 \mathrm{~nm}$ & $0.28 \pm 0.10$ & $0.39 \pm 0.10$ \\
$100 \mathrm{~nm}$ & $0.30 \pm 0.10$ & $0.44 \pm 0.10$ \\
$120 \mathrm{~nm}$ & $0.33 \pm 0.11$ & $0.49 \pm 0.13$ \\
\hline
\end{tabular}

the chemical dispersion is reduced with increasing particle size. $60 \mathrm{~nm}$ particles exhibit the highest dispersion especially for the Chios fire, suggesting that the smaller particles are a mixture of freshly emitted BB particles and particles formed from the condensation of organics during the transport from the fire location to Finokalia, as organics become less volatile with atmospheric processing, increasing the chemical dispersion. The 80 and $100 \mathrm{~nm}$ particles from the Chios fire have high $\sigma(\kappa) / \kappa$ values while the ones from Euboea and Andros have considerably lower values, demonstrating the magnitude of the Chios fire and the degree of atmospheric processing that has taken place. Finally, $120 \mathrm{~nm}$ particles always have a low chemical dispersion, with $\sigma(\kappa) / \kappa$ values close to the instrument limit. Nevertheless, the chemical dispersion of all particle sizes appears to be influenced by the presence of $\mathrm{BB}$, as there is an average relative increase of $\sigma(\kappa) / \kappa$ values of $21,28,41$ and $43 \%$ for $60,80,100$ and $120 \mathrm{~nm}$ particles, respectively, before and during the event. The increased chemical dispersion of particles smaller than $80 \mathrm{~nm}$ can therefore be attributed to the heterogeneity of sources of these particles (which is also seen by CALIOP, Fig. 3c) combined with lack of extensive cloud processing because the particles are too small to activate in boundary layer clouds in the region (Sect. 3.8). For larger particles, the chemical dispersion may be due to mixing with other types of aerosol that are not identified by the ACSM; microphysical processing such as condensational growth and cloud processing may be the reason why they exhibit a smaller chemical dispersion than smaller particles. Indeed, the surface area distribution (Fig. S1 of the Supplement) peaks at around $200 \mathrm{~nm}$, which means that condensation of SOA mass is most effective in that size range. Coagulation and condensation continuously occur together with any new source and with NPF during atmospheric transport (Triantafyllou et al., 2016; Kalkavouras et al., 2016), but cloud processing mixes everything and makes it completely homogeneous at the respective activation diameter that corresponds to each fire event. In terms of aerosol microphysical processes, numerical simulations indicate that for half a day of ageing under moderately polluted conditions, coagulation has been found to internally mix almost all particles above $0.2 \mu \mathrm{m}$, and smaller particles to a lesser extent (e.g., Jacobson, 2002). Condensation, for the same time scale, increases the fractional coating of small particles rather than large ones.
Table 3. Percentage of externally mixed samples $\left(B_{\mathrm{f}}\right)$, the hygroscopic parameter of the less and more hygroscopic mode $\left(\kappa_{1}, \kappa_{2}\right)$, respectively, and the number fraction of particles residing in the less hygroscopic mode $\left(N_{\mathrm{f} 1}\right)$ during the Chios event (20-21 August 2012).

\begin{tabular}{rrccc}
\hline$d_{\mathrm{p}}(\mathrm{nm})$ & $B_{\mathrm{f}}(\%)$ & $\kappa_{1}$ & $N_{\mathrm{f} 1}$ & $\kappa_{2}$ \\
\hline 60 & 6.90 & $0.05 \pm 0.02$ & $0.17 \pm 0.06$ & $0.18 \pm 0.01$ \\
80 & 20.0 & $0.05 \pm 0.02$ & $0.33 \pm 0.14$ & $0.19 \pm 0.03$ \\
100 & 23.0 & $0.06 \pm 0.03$ & $0.43 \pm 0.24$ & $0.21 \pm 0.04$ \\
120 & 30.4 & $0.05 \pm 0.03$ & $0.47 \pm 0.19$ & $0.20 \pm 0.04$ \\
\hline
\end{tabular}

\subsection{Particle growth factors during the fire events}

From the concurrent HTDMA growth-factor measurements at subsaturated conditions we calculated the corresponding $\kappa_{\text {HTDMA }}$ values. During the focus period of the biomassburning events as well as a few days before and after the events, the grand majority of the HTDMA data exhibited unimodal distributions, indicating that all selected particle fractions were internally mixed. Bimodal hygroscopicity distributions were only observed during the arrival of the smoke plumes from the most intense events and therefore are not taken into account for the comparison study between CFSTGC and HTDMA-derived $\kappa$ values. Average CFSTGCderived $\kappa_{\mathrm{CCN}}$ values and HTDMA-derived $\kappa_{\mathrm{HTDMA}}$ values for the selected particles sizes are given in Table 2. On average, $\kappa_{\text {HTDMA }}$ values are somewhat lower than the respective $\kappa_{\mathrm{CCN}}$ values for the smaller particles, while the difference between them is larger for the larger particle sizes. Nevertheless, both time series follow the same trend and values are consistent within $\pm 30 \%\left(\kappa_{\mathrm{HTDMA}}=0.854 \times \kappa_{\mathrm{CCN}}, R^{2}=\right.$ 0.87; Fig. S2 in the Supplement). Owing to non-ideality in the aqueous phase, partial solubility of the organics and the existence of multiple phases under subsaturated conditions, HTDMA-derived $\kappa_{\text {HTDMA }}$ values may indeed be lower than the corresponding $\mathrm{CCN}$-derived ones. In the study of Wu et al. (2013), $\kappa$ derived from CCN measurements was also roughly $30 \%$ higher than that determined from hygroscopic growth measurements. Similar effects are also seen for laboratory-generated aerosols composed of single and multiple compounds (Petters and Kreidenweis, 2007). Apart from non-ideality solution effects, the presence of surfactants produced during biomass-burning events (Asa-Awuku et al., 2008) may also increase the discrepancies between $\kappa$ HTDMA and $\kappa$-CCN (Ruehl et al., 2012). Other studies also note similar magnitudes of difference between CFSTGC and HTDMA-derived $\kappa$ values (e.g., Prenni et al., 2007; Massoli et al., 2010; Cerully et al., 2011).

The probability distribution of growth factors in the HTDMA gives an independent measure of particle mixing state. During the two most intense fire events (i.e., during the Chios and Euboea fire), where the smoke plume had the least amount of transit and atmospheric processing time, all sizes 

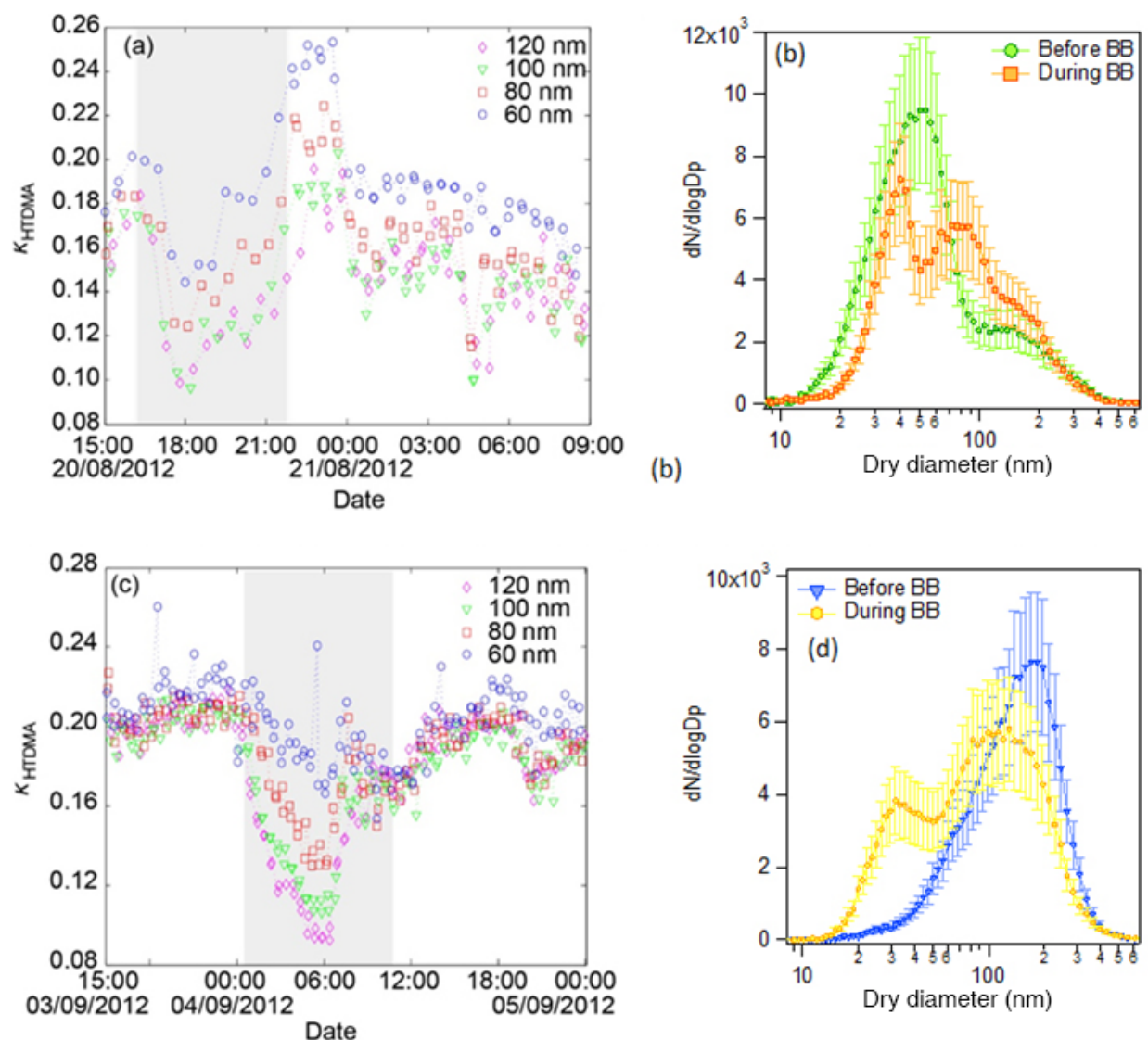

Figure 7. Hygroscopicity parameters derived from the HTDMA (a, c) and number size distributions from the SMPS (b, d) for the Chios and Euboea fire events, respectively. The shaded areas represent the smoke plume influence period.

Table 4. Same as Table 3, during the Euboea event (3-5 September 2012).

\begin{tabular}{rrccc}
\hline$d_{\mathrm{p}}(\mathrm{nm})$ & $B_{\mathrm{f}}(\%)$ & $\kappa_{1}$ & $N_{\mathrm{f} 1}$ & $\kappa_{2}$ \\
\hline 60 & 5.30 & $0.09 \pm 0.07$ & $0.37 \pm 0.34$ & $0.31 \pm 0.19$ \\
80 & 15.2 & $0.06 \pm 0.04$ & $0.31 \pm 0.17$ & $0.20 \pm 0.03$ \\
100 & 26.5 & $0.05 \pm 0.03$ & $0.39 \pm 0.19$ & $0.19 \pm 0.03$ \\
120 & 28.2 & $0.05 \pm 0.03$ & $0.40 \pm 0.19$ & $0.19 \pm 0.03$ \\
\hline
\end{tabular}

exhibited two different hygroscopic modes (Tables 3 and 4; Fig. S3 in the Supplement). These distinct modes were not observed during the other two events, owing to a longer processing time that allowed for condensation growth and mixing of the populations. Figure 7 portrays in the left-hand panels the $\overline{\kappa_{\text {HTDMA }}}$ (estimated using Eq. 6) for the sampled particle sizes during the Chios and Euboea fires. The righthand panels show the respective particle size distributions obtained by the concurrent SMPS measurements, revealing the presence of different particle modes. It should be noted that values differ from the respective $\kappa_{\mathrm{CCN}}$ values, under subsaturated conditions, because if some particles do not grow inside the HTDMA they are directly assigned with a growth factor equal to one (i.e., $\kappa=0$ ), subsequently reducing considerably the derived kappa value. These hydrophobic particles are likely not fully counted by the CFSTGC and hence do not contribute to the average $\kappa_{\mathrm{CCN}}$. During the arrival of the smoke-influenced air masses, there is a decrease in the hygroscopicity of all measured sizes. At the same time a bimodal distribution was observed by the SMPS (far right panels), indicative of two groups of particles, which can be partially due to the presence of freshly emitted particles (i.e., smaller mode) in combination with larger, more processed ones. Adler et al. (2011) had also observed a shift in the average mode diameter of size distributions from $86 \pm 8 \mathrm{~nm}$ for freshly emitted BBOA to $114 \pm 7 \mathrm{~nm}$ for processed BBOA. This further supports the observed higher chemical dispersion in the smaller particle sizes (Sect. 3.5).

A similar behavior when the sampled particles influenced by biomass burning were exposed to subsaturated conditions has been reported by Rissler et al. (2006). In those measurements the hygroscopic growth of the sampled particles when exposed to $90 \% \mathrm{RH}$ showed that there was an external mixture of a nearly hydrophobic $\left(g_{(\mathrm{RH})}=1.09\right.$ for $100 \mathrm{~nm}$ particles) and a moderately hygroscopic $\left(g_{(\mathrm{RH})}=1.26\right)$ population. This reinforces our observations from the $\mathrm{CCN}$ mea- 
surements, where for super-saturated conditions, the activation fraction of mainly the $60 \mathrm{~nm}$ particles decreased significantly under the influence of smoke. A possible explanation for why the activation fractions of the other size ranges remain close to unity during the smoke influence may result from the cloud processing of these sizes and their mixing with background particles, contributing to their hygroscopicity and chemical dispersion. The overall characteristics are expected to be determined by the number fraction of the two modes in each size, combined with the occurrence of these two modes. If the presence of the bimodal samples is limited (less than $30 \%$ ), then even though the fraction of the less hygroscopic mode may be as high as $45 \%$, the overall activation fractions might not be influenced. For the first event (2021 August), which was the most intense, the externally mixed samples represent almost $25 \%$ of the total sampled aerosol, with the occurrence of the bimodal samples increasing with increasing diameter (Table 3). It appears that in the bimodal samples the less hygroscopic mode initially dominates followed by a progressive dominance of the hygroscopic mode. It also appears that the increase in the less hygroscopic fraction coincides with the plume arrival time and the increase of the BBOA component, further supporting our findings of external mixing. During the second event (3-5 September) the bimodal samples increase, once more, with increasing diameter ( $5 \%$ for $60 \mathrm{~nm}$ to $28 \%$ for $120 \mathrm{~nm}$ particles). The less hygroscopic fraction in this case was dominant in approximately $33 \%$ of the samples, although this more hygroscopic mode had a $\kappa_{\text {HTDMA }}$ value of 0.2 during the plume arrival time (Table 4). The more hygroscopic mode is therefore dominant in number for all sampled particles, which would explain that the activation fraction of the larger accumulation mode particles are not significantly affected by the presence of the less hygroscopic mode. On the other hand, the reason for the reduction of the activation fraction of $60 \mathrm{~nm}$ particles, apart from their hygroscopicity, can also be their different source and size, as during the events, the less hygroscopic mode is probably not activated, thus not detected by the $\mathrm{CCN}$ counter. This is not the case for the larger particles, for example, $80 \mathrm{~nm}$ particles having a low $\kappa_{\mathrm{HTDMA}}=0.06$ will still activate at the highest supersaturations sampled $(s=0.67 \%)$.

\subsection{Inferring size-dependent chemical composition and organic hygroscopicity}

We assume that the total aerosol hygroscopicity can be represented as the sum of the contribution of the different aerosol components:

$\kappa=\sum_{j} \varepsilon_{j} \kappa_{j}$,

where $\varepsilon_{j}$ and $\kappa_{j}$ are the volume fraction and hygroscopicity parameters of each species, respectively (Petters and Kreidenweis, 2007). With the use of this equation, and by assuming that the aerosol is a mixture of an organic and inorganic component, with the inorganic component being represented by ammonium sulfate, the total measured hygroscopicity, can be expressed by the following sum:

$\kappa=\varepsilon_{\text {inorg }} \kappa_{\text {inorg }}+\varepsilon_{\text {org }} \kappa_{\text {org }}$.

Prior studies at Finokalia (Bougiatioti et al., 2009, 2011) have determined $\kappa_{\text {org }}=0.158$ and $\kappa_{\text {inorg }}=0.6$. Assuming this still applies and $\varepsilon_{\text {inorg }}+\varepsilon_{\text {org }}=1$, Eq. (8) can be used to infer the volume fractions of organics and ammonium sulfate for the four different sizes, excluding the days of direct biomass-burning influence. From this we obtain that $60 \mathrm{~nm}$ particles, on average, are composed of $82 \%$ organics and $18 \%$ ammonium sulfate; $80 \mathrm{~nm}$ particles, of $44 \%$ organics and $55 \%$ ammonium sulfate, and the larger particles contain a much larger fraction of ammonium sulfate (67 and $78 \%$ for 100 and $120 \mathrm{~nm}$ particles). This reinforces our conclusion based on the hygroscopicity measurements that the smaller particles are mostly composed of organic material. These observations are in agreement with similar observations reported by Bezantakos et al. (2013) in the region of the northern Aegean Sea.

The above approach can also be applied to the data from the fire events as follows: we use only the larger size $(120 \mathrm{~nm})$ as from the former CCN studies in the area it was established that the hygroscopicity of the larger particles is close to the "bulk" hygroscopicity of the sampled aerosol $\left(\mathrm{PM}_{1}\right)$, which is constrained from the ACSM measurements (Bougiatioti et al., 2011). To evaluate the importance of the assumptions made in inferring the organic hygroscopicity from chemical composition, $\kappa_{\text {org }}$ was additionally determined by applying Eq. (8) for the $120 \mathrm{~nm}$ particles, where a set of $\kappa$ equations is produced $(n=228)$. Multivariable regression analysis within the excel environment is subsequently applied in order to determine the organic and inorganic component of the total hygroscopicity during the fire events. From the results we found that $\kappa_{\text {inorg }}=0.61 \pm 0.03$ and $\kappa_{\text {org }}=0.137 \pm 0.02$, which are very similar to values determined by Bougiatioti et al. $(2009,2011)$. The confidence level is $95 \%$ and the resulting fit has an $R^{2}=0.91$ and $p$ values are smaller than $8 \times 10^{-7}$ for both components.

Taking the analysis one step further, we attempt a source apportionment of the organic hygroscopicity by its attribution to different factors. positive matrix factorization (PMF) analysis was applied to the time series of data under the direct influence of biomass burning. A detailed discussion of the PMF results can be found in Bougiatioti et al. (2014). During the focus period, three subtypes of organic aerosol (OA) were identified, namely biomass-burning OA (BBOA), an OOA associated with biomass burning (OOA-BB) and a highly oxygenated OOA, having relative contributions of 22 , 32 and $46 \%$, respectively. With the chemical composition measurements of the ACSM applied to the larger particle size $(120 \mathrm{~nm})$ combined with the respective $\kappa_{\mathrm{CCN}}$, we use the following equation to determine the hygroscopicity parameter 
of each factor:

$$
\begin{aligned}
\kappa= & \left(1-\varepsilon_{\mathrm{org}}\right) \kappa_{\mathrm{inorg}}+\varepsilon_{\mathrm{BBOA}} \kappa_{\mathrm{BBOA}} \\
& +\varepsilon_{\mathrm{OOA}-\mathrm{BB}} \kappa_{\mathrm{OOA}-\mathrm{BB}}+\varepsilon_{\mathrm{OOA}} \kappa_{\mathrm{OOA}} .
\end{aligned}
$$

Once again a set of $228 \kappa$ equations is produced and multivariable regression analysis is applied in order to deconvolve the organic hygroscopicity to its 3 subtypes. The confidence level once more is $95 \%$ and the resulting fit has an $R^{2}=0.93$, with $p$ values smaller than 0.001 . It occurs that $\kappa_{\text {inorg }}=0.62 \pm 0.04, \kappa_{\mathrm{BBOA}}=0.057 \pm 0.07, \kappa_{\mathrm{OOA}-\mathrm{BB}}=$ $0.138 \pm 0.11$ and $\kappa_{\mathrm{OOA}}=0.169 \pm 0.09$. As the occurrence of two modes of different hygroscopicity, seen by the HTDMA during the arrival of the smoke, coincide with the identification of BBOA by the ACSM, it is interesting to see that the inferred hygroscopicity for the freshly emitted BBOA is very close to the hygroscopicity obtained by the HTDMA for the less hygroscopic component when two particle populations were present during the events (Tables 3 and 4, Sect. 3.6). When comparing the obtained hygroscopicity with the level of oxidation of each factor $(\mathrm{O}: \mathrm{C}=0.2$ for $\mathrm{BBOA}, 0.9$ for OOA-BB and 1.2 for OOA; Bougiatioti et al., 2014) it occurs that the less hygroscopic component is also the least oxygenated and that hygroscopicity increases with increasing $\mathrm{O}: \mathrm{C}$ ratio. The calculated values are also comparable to the $\kappa$ obtained by Chang et al. (2010) for the oxygenated organic component (OOA-1, OOA-2 and BBOA) of rural aerosol $\left(\kappa_{\mathrm{ox}}=0.22 \pm 0.04\right)$. They also found increased hygroscopicity with increasing ageing and degree of oxidation. Furthermore, the total organic hygroscopicity is very similar to that of the processed organic aerosol components, which make up almost $80 \%$ of the organic aerosol. Finally, based on the derived hygroscopicities for the BBOA and the processed BBOA (OOA-BB), it seems that the biomass-burning organic aerosol becomes more hygroscopic by almost a factor of two with atmospheric processing.

Using the average diurnal profiles obtained from the PMF analysis combined with the corresponding mass fractions of each component and the inferred hygroscopicity parameter of each, we estimated the contribution of each factor to the overall $\kappa_{\text {org }}$ and the total aerosol hygroscopicity. Figure 8 presents the resulting diurnal profiles from which it is clear that the grand majority of the organic hygroscopicity originates from the aged, very oxidized OOA. BBOA contributes around $7 \%$ to the organic hygroscopicity $(2.2 \%$ to the overall aerosol hygroscopicity), which is small but not negligible, as it can be seen that when the BBOA contribution is highest, there is an important decrease in the $\kappa_{\text {org }}$. Overall, organic aerosol associated with biomass burning can account for almost $35 \%$ of the organic hygroscopicity. By using the approach of Guo et al. (2015), where particle water is predicted using meteorological observations (relative humidity, temperature), aerosol composition and thermodynamic modeling (ISORROPIA-II; Fountoukis and Nenes, 2007), the LWC associated with the organic fraction is calculated. We find that

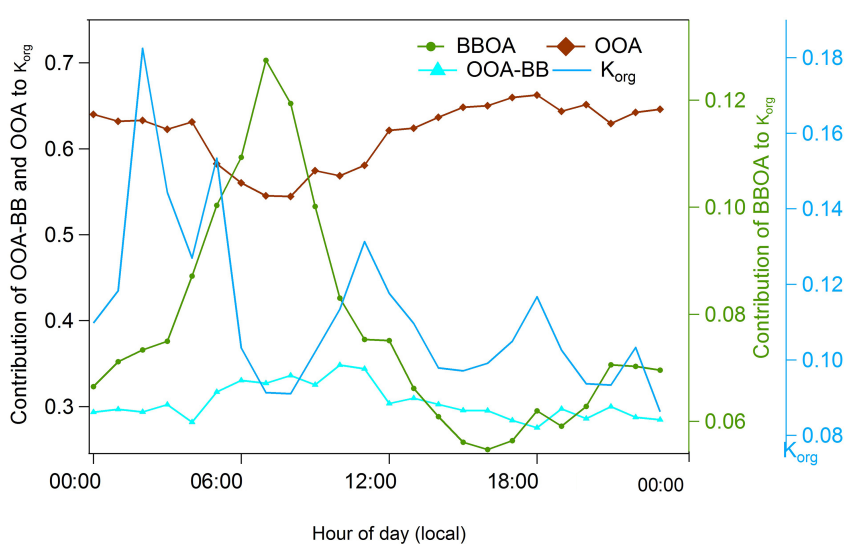

Figure 8. Average diurnal contribution of each organic aerosol factor to the $\kappa_{\text {org }}$ computed by multiplying the mass fraction by the corresponding inferred hygroscopicity parameter and the predicted diurnal profile of the total $\kappa_{\text {org }}$ in the ambient aerosol.

although the freshly emitted BBOA contributes merely $1.2 \%$ to the total organic water of the aerosol, the contribution of the processed OOA-BB is almost $33 \%$. It is therefore clear that in the presence of biomass-burning aerosol, both aerosol hygroscopicity and LWC may be influenced, thus affecting the overall direct and indirect aerosol radiative effects.

\subsection{BB influence on droplet formation}

The direct microphysical link between aerosol and clouds is the activation process, where a fraction of the aerosol contained within an ascending cloud parcel experiences unconstrained growth and activates to form cloud droplets. State-of-the-art cloud droplet parameterizations (Fountoukis and Nenes, 2005; Ghan et al., 2011; Morales Betancourt and Nenes, 2014) can accurately and rapidly calculate the droplet number $\left(N_{\mathrm{d}}\right)$ and maximum supersaturation $\left(S_{\max }\right)$ that would form in a cloud, given knowledge of the aerosol distribution, composition and updraft velocity. Using the aerosol and hygroscopicity observations from all four BB events, we calculate the droplet number and supersaturation for clouds forming in the vicinity of Finokalia, using the droplet parameterizations based on the "population splitting concept" of Nenes and Seinfeld (2003), later improved by Barahona et al. (2010) and Morales and Nenes (2014). In the calculations of droplet number, the size distribution is represented by the sectional approach, derived directly from the SMPS distribution files. Values of updraft velocity are not known for Finokalia, but have been calculated from high-resolution airborne measurements performed in the area, under similar atmospheric conditions (Kalkavouras et al., 2016); simulations suggest that the distribution of vertical velocities in the boundary layer around Finokalia displays a spectral dispersion of $\sigma_{\mathrm{w}}=0.2-0.3 \mathrm{~m} \mathrm{~s}^{-1}$ around a mean average value of 0.3 . These values are generally consistent with vertical velocities observed in marine boundary lay- 
ers (e.g., Meskhidze et al., 2005; Ghate et al., 2011). Given this, we can employ the characteristic velocity approach of Morales and Nenes (2010) when applying the droplet parameterization to obtain velocity PDF-averaged values of CDNC and $S_{\max }$. As a sensitivity test, we also consider calculations for a convective boundary layer $\left(\sigma_{\mathrm{w}}=0.6 \mathrm{~m} \mathrm{~s}^{-1}\right)$. The calculation of PDF-averaged values of CDNC and $S_{\max }$ is carried out for every distribution of aerosol number and composition measured for all four biomass-burning events ( $5 \mathrm{~min}$ resolution distributions from the SMPS measurements for at least two days for each event). Results of all the calculations are shown in Fig. 9. As a reference, the time series of the BBOA component is also portrayed.

For all events, the arrival of the smoke plume is followed by a considerable depression in the maximum supersaturation (relative average decrease $(11.9 \pm 2.7) \%$ for $\sigma_{\mathrm{w}}=$ $0.3 \mathrm{~m} \mathrm{~s}^{-1}$ and $(18 \pm 5.9) \%$ for $\left.\sigma_{\mathrm{w}}=0.6 \mathrm{~m} \mathrm{~s}^{-1}\right)$ that develops in clouds. This is a result of the enhanced competition for water vapor during cloud droplet formation for clouds affected by biomass-burning smoke. The negative feedback of aerosol on supersaturation partially mitigates the observed increases in CCN to the point where clouds are highly insensitive to the large aerosol concentration increases (Moore et al., 2013; Zamora et al., 2016). As expected, increases in the updraft velocity $\left(\sigma_{\mathrm{w}}=0.6 \mathrm{~m} \mathrm{~s}^{-1}\right)$ reduces the competition of $\mathrm{CCN}$ for water vapor, allowing $S_{\max }$ to increase by almost $30 \%$. The respective perturbation of $N_{\mathrm{d}}$ from BB influences by doubling the updraft velocity increases to $54 \%$ on average (from 9.3 to $24.2 \%$ for Chios, from 8.5 to $15.2 \%$ for Croatia, from 11 to $18.8 \%$ for Euboea and from 4 to $13.8 \%$ for Andros). The low supersaturations developed in BB-influenced clouds (here, as low as $0.06 \%$ ) shifts the size of particles affected by cloud processing to the largest particles (cutoff diameters before and during the Chios intense event were on average 133 and $109 \mathrm{~nm}$, while during the other events they were on average 154.8 and $129.3 \mathrm{~nm}$ ). Interestingly, the notable drop in chemical dispersion in the $100-120 \mathrm{~nm}$ particle sizes are consistent with the notion that cloud processing would considerably enhance their degree of internal mixing.

The degree to which BB influences $N_{\mathrm{d}}$ does not depend only on the value of updraft velocity and the intensity of the BB event; it also depends on the background aerosol. This is because the background preconditions the clouds and determines the levels of supersaturation that develop prior to the arrival of the BB aerosol. Highly polluted background generally means larger insensitivity of $N_{\mathrm{d}}$ to BB. This is shown clearly in Fig. 10, which presents the droplet number concentration (top panel) and cloud maximum supersaturation (bottom panel) for each fire event as a function of BB influence, expressed by the sum of BBOA and OOA-BB ACSM factors. From the figure one can clearly see that when the background levels aerosol decreases (indicated by the lower $N_{\mathrm{d}}$ and higher $S_{\max }$ at the low end of BB factor concentrations, which is characteristic of the Coatia and Chios fires), $N_{\mathrm{d}}$ responds to increases in $\mathrm{BB}$, up to the point where the clouds become "saturated" with aerosol (with a supersaturation around $0.08 \%$ and below, indicated by the shaded areas in Fig. 10) and are insensitive to additional increases in BB. Euboea and Andros fires already have a high background, so the cloud droplet number is relatively insensitive to BB influence.

Finally, we estimated the relative contribution of chemical composition (from $\kappa$ ) and aerosol number concentration to the $N_{\mathrm{d}}$, expressed by the average of the partial derivatives of $\mathrm{d} N_{\mathrm{d}} / \mathrm{d} N_{\mathrm{a}}$ and $\mathrm{d} N_{\mathrm{d}} / \mathrm{d} N_{\kappa}$ and using the following equations:

$\sigma^{2} N_{\mathrm{d}}=\sigma N_{\mathrm{a}} \frac{\overline{\partial N_{\mathrm{d}}}}{\partial N_{\mathrm{a}}}+\sigma \kappa \frac{\overline{\partial N_{\mathrm{d}}}}{\partial N_{\kappa}}$,

where $\sigma^{2}$ is the variance of the droplet number $\left(N_{\mathrm{d}}\right), \sigma N_{\mathrm{a}}$ is the standard deviation of the total aerosol number and $\sigma \kappa$ is the standard deviation of the hygroscopicity parameter. The relative contribution of each of the total aerosol numbers $\left(\varepsilon N_{\mathrm{a}}\right)$ and hygroscopicity parameters $(\varepsilon \kappa)$ to the droplet number is estimated:

$\varepsilon \kappa_{N_{\mathrm{d}}}=\sigma \kappa \frac{\frac{\frac{\partial N_{\mathrm{d}}}{\mathrm{d} N_{\kappa}}}{\sigma^{2} N_{\mathrm{d}}}}{\varepsilon N_{\mathrm{a}_{N_{\mathrm{d}}}}=\sigma N_{\mathrm{a}} \frac{\frac{\frac{\partial N_{\mathrm{d}}}{\partial N_{\mathrm{a}}}}{\sigma^{2} N_{\mathrm{d}}} .}{}}$.

The results provided in Table 5 demonstrate that there are differences between the fire events, which can be attributed to the intensity of each event and thus the resulting concentrations, and the distance from the fire, thus the mixing and dilution during transport. The highest variance in $N_{\mathrm{d}}$ was calculated for the Andros event, which exhibited the lowest variability in $N_{\text {aerosol }}$ and the lowest variance was calculated for the Chios, followed by the Croatia event, which exhibited a variability in $N_{\text {aerosol }}$ of more than 1500 particles $\left(\mathrm{cm}^{-3}\right)$. From the relative contribution of the total aerosol number and chemical composition to $N_{\mathrm{d}}$, it can be seen that the closer the fire event is, the larger the contribution of aerosol number to the potential CDNC. As we move further away (e.g., Chios and Croatia) and the distance increases, the influence of the chemical composition becomes increasingly important, given the decrease of concentrations and dilution during transport.

\section{Summary and conclusions}

This study provides CCN concentrations, subsaturated hygroscopicity, mixing state of size-selected aerosol particles and their impact on cloud formation in air masses influenced by summer biomass-burning (BB) events in the eastern Mediterranean. The uniqueness of the examined dataset lies in the nature of the fires, where smoke is mostly generated from isolated fires and subsequently transported and 

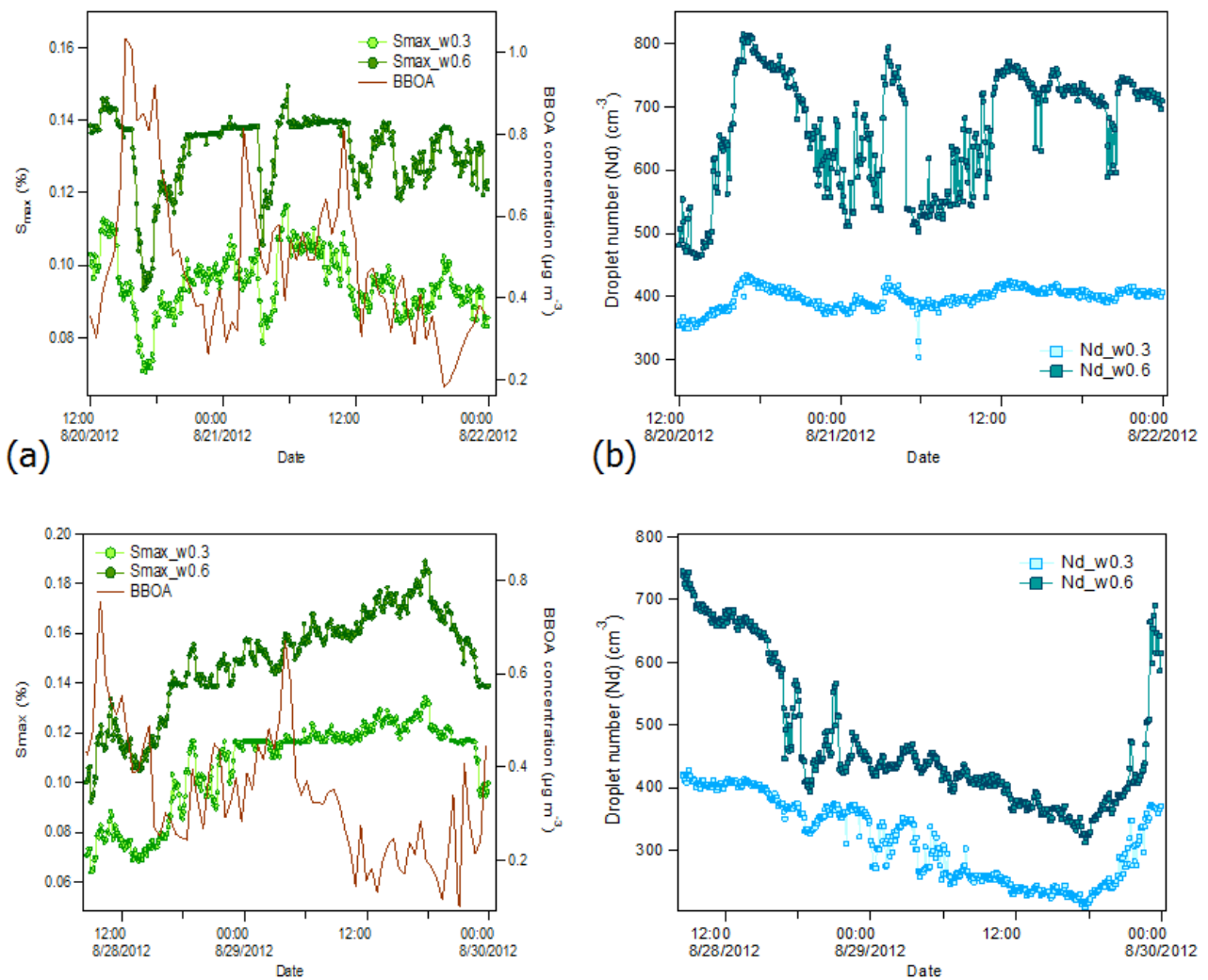

(c)

(d)
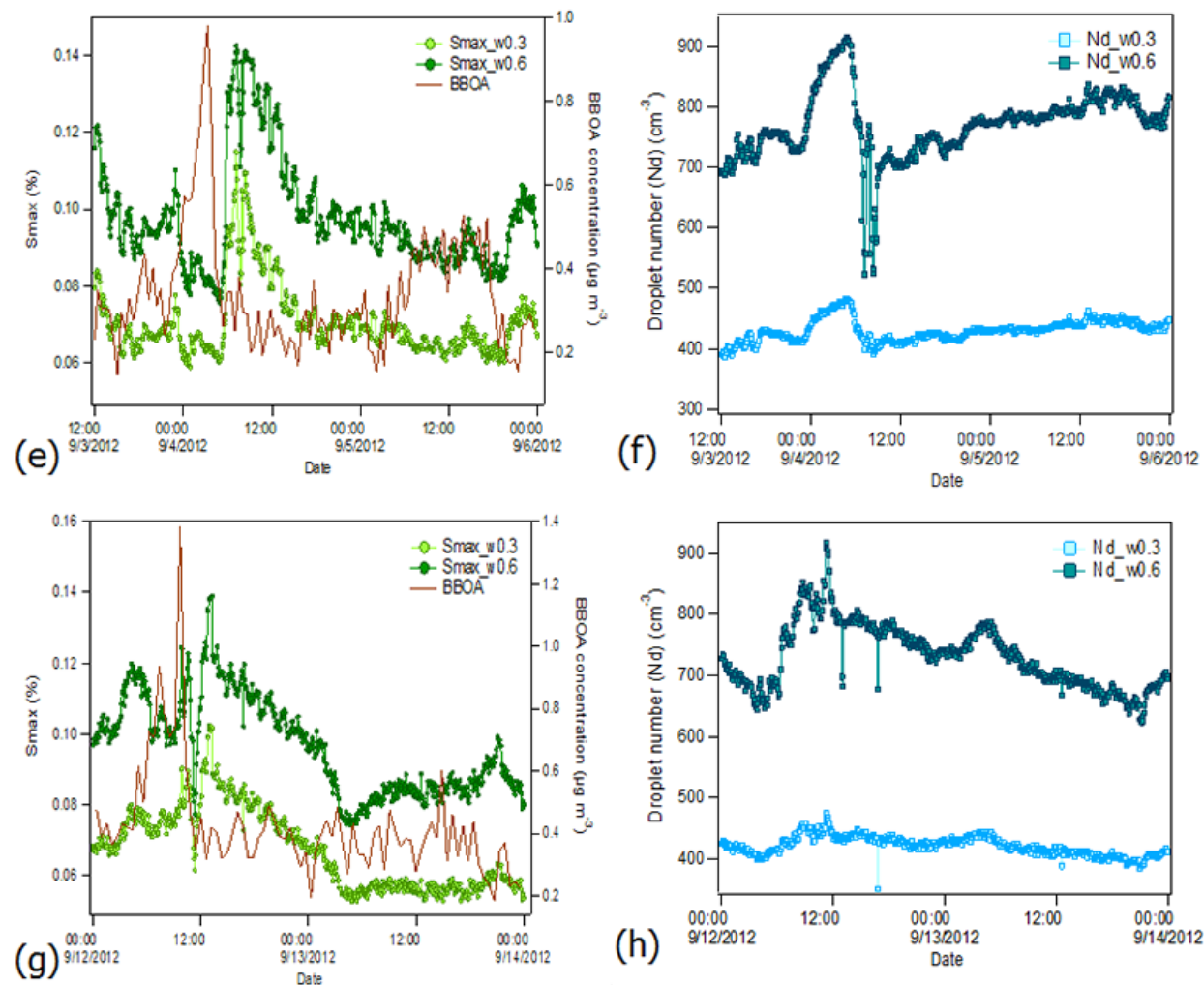

Figure 9. Maximum supersaturation $\left(S_{\max }\right)$ (left panels) and potential droplet number $\left(N_{\mathrm{d}}\right)$ (right panels) for the four fire events of Chios (a, b), Croatia (c, d), Euboea $(\mathbf{e}, \mathbf{f})$ and $\operatorname{Andros}(\mathbf{g}, \mathbf{h})$. 
Table 5. Variance of $N_{\mathrm{d}}$ and relative contribution to this variance of aerosol number and chemical composition for the four fire events.

\begin{tabular}{|c|c|c|c|c|c|c|}
\hline & \multicolumn{2}{|c|}{ Variance $N_{\mathrm{d}}$} & \multicolumn{2}{|c|}{ Contribution_א } & \multicolumn{2}{|c|}{ Contribution_ $N_{\text {aerosol }}$} \\
\hline & $w=0.3$ & $w=0.6$ & $w=0.3$ & $w=0.6$ & $w=0.3$ & $w=0.6$ \\
\hline Chios & 13.8 & 18.1 & $17.7 \%$ & $12.6 \%$ & $82.3 \%$ & $87.4 \%$ \\
\hline Croatia & 34.4 & 47.7 & $26.7 \%$ & $25.2 \%$ & $73.3 \%$ & $74.8 \%$ \\
\hline Euboea & 60.9 & 111.3 & $1.10 \%$ & $2.2 \%$ & $98.9 \%$ & $97.8 \%$ \\
\hline Andros & 164.2 & 307.8 & $0.10 \%$ & $0.15 \%$ & $99.9 \%$ & $99.8 \%$ \\
\hline
\end{tabular}
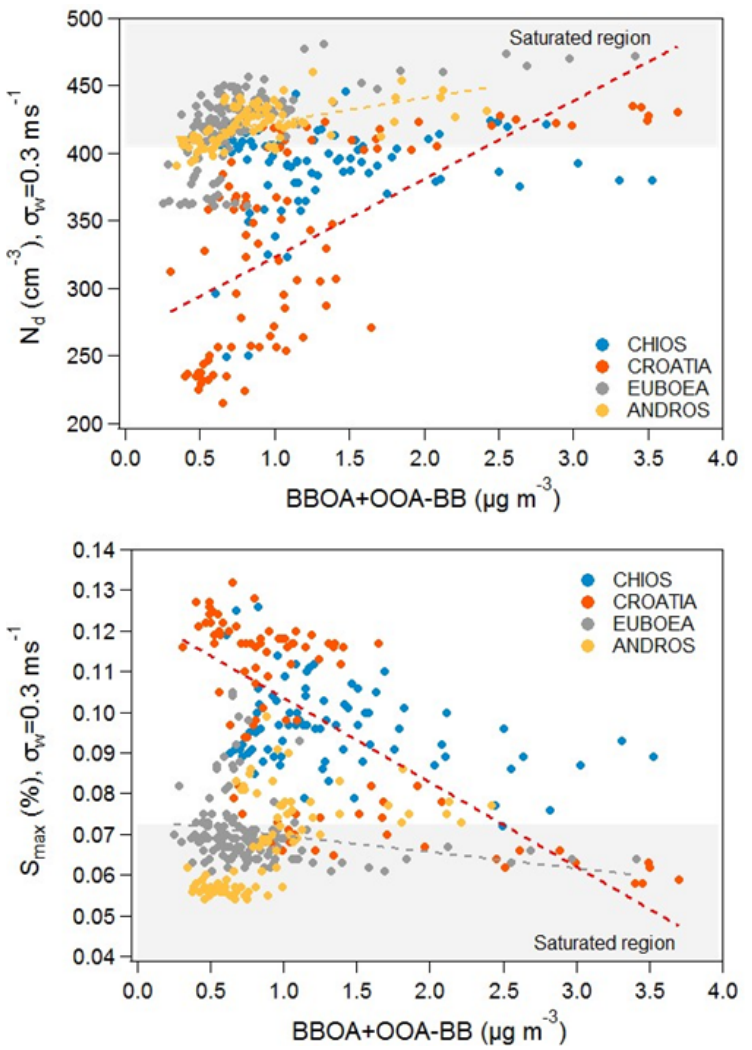

Figure 10. Droplet number concentration (top panel) and cloud maximum supersaturation (bottom panel) for each fire event as a function of BB influence, expressed by the sum of BBOA and OOABB ACSM factors.

aged from a few hours to days before sampling. The presence of smoke in the most intense events is clearly identified by CALIPSO lidar remote sensing and the MODIS FIRMS product, while chemical markers and back-trajectory analysis confirm the influence of BB in every event. During each event, the contribution of organics and $\mathrm{BC}$ increased significantly while the concentration of sulfates decreased. This is shown to affect the hygroscopicity as well as the mixing state of the particles. The fire events had a direct influence on the total particle $(\mathrm{CN})$ and $\mathrm{CCN}$ concentrations across all sizes; particle sizes larger than $100 \mathrm{~nm}$ exhibited an increase in absolute number of more than $50 \%$ and up to $30 \%$ for particles in the $60-80 \mathrm{~nm}$ range. The fraction of the smaller particles acting as $\mathrm{CCN}$ even at the highest level of measured supersaturation $(0.6 \% s)$, however, went significantly below unity in the presence of smoke. This and the overall value of hygroscopicity indicate that fewer $\mathrm{CCN}$-active organic compounds are the dominant component of $60 \mathrm{~nm}$ and smaller particles (up to $82 \%$ of mass), while particles larger than $100 \mathrm{~nm}$ contain a much larger fraction of ammonium sulfate. The subsaturated hygroscopicity measurements confirm this, as $60 \mathrm{~nm}$ particles exhibited the lowest hygroscopic growth.

During the arrival of the biomass-burning-laden air masses, the average hygroscopicity parameters of all particle sizes converged to values between $0.2-0.3$, which can be attributed to different chemical composition of all particles during these events, compared to background conditions. The hygroscopicity distributions and chemical dispersion analysis of the CCN data clearly show that smaller particles exhibit higher chemical diversity (variance in hygroscopicity equal to $0.15 \kappa$ units) than larger particles (variance in hygroscopicity less than $0.1 \kappa$ units). This size-dependent mixing state may reflect the presence of different aerosol sources with characteristic sizes (e.g., sea-salt, pollution in addition to BB) and size-dependent chemical composition; the fact that smaller particles are less mixed than larger particles - together with the background aerosol being composed of a large mode with a distinct chemical composition - suggests that the smaller particles are an external mixture of freshly emitted and secondarily formed particles that retain a large degree of mixing. Larger particles are further aged and subject to coagulation, condensation of secondary species and cloud processing, all of which tend to homogenize the aerosol. However, two aerosol populations with distinct hygroscopicity were seen even at the largest sizes sampled during the most intense fire events. Nevertheless, their occurrence is limited and the overall activation of larger particles appears to be unaffected by the presence of these two populations. In terms of cloud processing effects, the largest particles that are predicted to form droplets in clouds in the vicinity of the sampling site indeed exhibit the lowest chemical dispersion. This supports the assumption of external mixing for smaller particles that originate from biomass burning having decreased activation fractions and provides a plausible explanation of why larger particles appear, based on their 
activation fractions, not to be affected as far as their $\mathrm{CCN}$ activity is concerned.

Using multivariable regression analysis and the volume fractions of organics and ammonium sulfate for the different particle sizes, we inferred the hygroscopicity of the organic fraction and found it equal to $0.115 \pm 0.017$, which is consistent with published values from the literature. Using the results obtained from the source apportionment of the organic fraction, we were able to deconvolve the organic hygroscopicity to its three subtypes. The hygroscopicity of freshly emitted BBOA was found to be around 0.06, while the hygroscopicity of atmospherically processed BBOA and highly oxidized organic aerosol were found to be 0.14 and 0.17 , respectively. The inferred hygroscopicity of each component and its oxidation state are in line with the overall organic aerosol values observed. From this and the trends of each factor with atmospheric age we conclude that the organic fraction of biomass-burning aerosol becomes more hygroscopic with atmospheric ageing. Overall, organic aerosol associated with biomass burning (freshly emitted and processed) can account for $10 \%$ of the total aerosol hygroscopicity (2.2 and $7.6 \%$ for BBOA and OOA-BB, respectively). For the observed levels of relative humidity and amounts of each organic aerosol factor, we estimate that BBOA and OOA-BB contribute anywhere between 1.2 and $32.6 \%$ of the total organic water of the aerosol.

Towards understanding the impacts of the observed BB on clouds, we study the behavior of cloud droplet formation for typical boundary layer conditions. For this, we apply a state-of-the-art cloud droplet formation parameterization to the observations, assuming typical values of updraft velocity for marine boundary layer clouds. We find that the very high concentrations of $\mathrm{CCN}$ during the influence of BB events tend to promote the competition for cloud water vapor and substantially depress the cloud supersaturation down to very low levels (even as low as $0.06 \%$ ). As a result, only the largest particles, from $110-150 \mathrm{~nm}$ in diameter and above, can activate to form cloud droplets. This also means that droplet number becomes highly insensitive to changes in aerosol in the presence of $\mathrm{BB}$; indeed clouds influenced by $\mathrm{BB}$ exhibit a relative decrease in maximum supersaturation by $12 \%$, while at the same time, BB augments the potential droplet number by $8.5 \%$. These results also support the chemical dispersion/mixing state analysis of the CCN data, as only the largest aerosol sizes sampled activate and are exposed to cloud processing. Based on the average sensitivity of droplet number to changes in aerosol number and composition, and observed variances thereof, we attribute the relative contribution of chemical composition and total aerosol number to the variance of droplet number. We find that the distance from the source is a key parameter that governs the importance of each parameter, with the influence of the chemical composition becoming increasingly important (controlling up to $25 \%$ of the droplet number variability) with growing distance from the source. Close to sources, the exclusive majority ( $98 \%$ and above) of the predicted droplet number variability is attributed to aerosol number variations. Therefore, although BB may strongly elevate CCN numbers, the relative impacts on cloud droplet number (compared to background levels) is eventually limited by water vapor availability and depends on the aerosol levels associated with the background.

\section{Data availability}

All data are available upon request from the corresponding authors.

\section{The Supplement related to this article is available online at doi:10.5194/acp-16-7389-2016-supplement.}

Acknowledgements. The work of A. Bougiatioti, A. Papayannis, P. Kokkalis was supported by the MACAVE research project and the work of N. Kalivitis by the FRONT research project, which are implemented within the framework of the action Supporting of Postdoctoral Researchers of the Operational Program Education and Lifelong Learning (action's beneficiary: General Secretariat for Research and Technology), and is co-financed by the European Social Fund (ESF) and the Greek State. This research has also been co-financed by the European Union (European Social Fund, ESF) and Greek national funds through the Operational Program "Education and Lifelong Learning" of the National Strategic Reference Framework (NSRF) - Research Funding Program: THALES, Investing in knowledge society through the European Social Fund. The financial support by the European Community through the ACTRIS Research Infrastructure Action and Bacchus project under the 7th Framework Programme (Grant Agreements no. 262254 and 603445, respectively) are gratefully acknowledged. A. Nenes acknowledges support from a Georgia Power Faculty Scholar Chair and a Cullen-Peck Faculty Fellowship. This study contributes to ChArMEx Work Packages 2 and 4 on chemical ageing and regional aerosol-climate interactions, respectively.

Edited by: F. Dulac

\section{References}

Adler, G., Flores, J. M., Abo Riziq, A., Borrmann, S., and Rudich, Y.: Chemical, physical, and optical evolution of biomass burning aerosols: a case study, Atmos. Chem. Phys., 11, 1491-1503, doi:10.5194/acp-11-1491-2011, 2011.

Andreae, M. O., Rosenfeld, D., Artaxo, P., Costa, A. A., Frank, G. P., Longo, K. M., and Silva Dias, M. A. F.: Smoking rain clouds over the Amazon, Science, 303, 1337-1342, 2004.

Asa-Awuku, A., Sullivan, A. P., Hennigan, C. J., Weber, R. J., and Nenes, A.: Investigation of molar volume and surfactant characteristics of water-soluble organic compounds in biomass burning aerosol, Atmos. Chem. Phys., 8, 799-812, doi:10.5194/acp8-799-2008, 2008. 
Barahona, D., West, R. E. L., Stier, P., Romakkaniemi, S., Kokkola, H., and Nenes, A.: Comprehensively accounting for the effect of giant $\mathrm{CCN}$ in cloud activation parameterizations, Atmos. Chem. Phys., 10, 2467-2473, doi:10.5194/acp-10-2467-2010, 2010.

Bezantakos, S., Barmpounis, K., Giamarelou, M., Bossioli, E., Tombrou, M., Mihalopoulos, N., Eleftheriadis, K., Kalogiros, J., D. Allan, J., Bacak, A., Percival, C. J., Coe, H., and Biskos, G.: Chemical composition and hygroscopic properties of aerosol particles over the Aegean Sea, Atmos. Chem. Phys., 13, 1159511608, doi:10.5194/acp-13-11595-2013, 2013.

Biskos, G., Paulsen, D., Russell, L. M., Buseck, P. R., and Martin, S. T.: Prompt deliquescence and efflorescence of aerosol nanoparticles, Atmos. Chem. Phys., 6, 4633-4642, doi:10.5194/acp-64633-2006, 2006.

Bougiatioti, A., Fountoukis, C., Kalivitis, N., Pandis, S. N., Nenes, A., and Mihalopoulos, N.: Cloud condensation nuclei measurements in the marine boundary layer of the Eastern Mediterranean: CCN closure and droplet growth kinetics, Atmos. Chem. Phys., 9, 7053-7066, doi:10.5194/acp-9-7053-2009, 2009.

Bougiatioti, A., Nenes, A., Fountoukis, C., Kalivitis, N., Pandis, S. N., and Mihalopoulos, N.: Size-resolved CCN distributions and activation kinetics of aged continental and marine aerosol, Atmos. Chem. Phys., 11, 8791-8808, doi:10.5194/acp-11-87912011, 2011.

Bougiatioti, A., Stavroulas, I., Kostenidou, E., Zarmpas, P., Theodosi, C., Kouvarakis, G., Canonaco, F., Prévôt, A. S. H., Nenes, A., Pandis, S. N., and Mihalopoulos, N.: Processing of biomassburning aerosol in the eastern Mediterranean during summertime, Atmos. Chem. Phys., 14, 4793-4807, doi:10.5194/acp-144793-2014, 2014.

Carlton, A. G. and Turpin, B. J.: Particle partitioning potential of organic compounds is highest in the Eastern US and driven by anthropogenic water, Atmos. Chem. Phys., 13, 10203-10214, doi:10.5194/acp-13-10203-2013, 2013.

Cerully, K. M., Raatikainen, T., Lance, S., Tkacik, D., Tiitta, P., Petäjä, T., Ehn, M., Kulmala, M., Worsnop, D. R., Laaksonen, A., Smith, J. N., and Nenes, A.: Aerosol hygroscopicity and CCN activation kinetics in a boreal forest environment during the 2007 EUCAARI campaign, Atmos. Chem. Phys., 11, 12369-12386, doi:10.5194/acp-11-12369-2011, 2011.

Cerully, K. M., Bougiatioti, A., Hite Jr., J. R., Guo, H., Xu, L., Ng, N. L., Weber, R., and Nenes, A.: On the link between hygroscopicity, volatility, and oxidation state of ambient and water-soluble aerosols in the southeastern United States, Atmos. Chem. Phys., 15, 8679-8694, doi:10.5194/acp-15-8679-2015, 2015.

Chang, R. Y.-W., Slowik, J. G., Shantz, N. C., Vlasenko, A., Liggio, J., Sjostedt, S. J., Leaitch, W. R., and Abbatt, J. P. D.: The hygroscopicity parameter $(\kappa)$ of ambient organic aerosol at a field site subject to biogenic and anthropogenic influences: relationship to degree of aerosol oxidation, Atmos. Chem. Phys., 10, 5047-5064, doi:10.5194/acp-10-5047-2010, 2010.

Dusek, U., Frank, G. P., Curtius, J., Drewnick, F., Schneider, J., Kürten, A., Rose, D., Andreae, M. O., Borrmann, S., and Pöschl, U.: Enhanced organic mass fraction and decreased hygroscopicity of cloud condensation nuclei (CCN) during NPF events, Geophys. Res. Lett., 37, L03804, doi:10.1029/2009GL040930, 2010.

Engelhart, G. J., Hennigan, C. J., Miracolo, M. A., Robinson, A. L., and Pandis, S. N.: Cloud condensation nuclei activity of fresh primary and aged biomass burning aerosol, Atmos. Chem. Phys., 12, 7285-7293, doi:10.5194/acp-12-7285-2012, 2012.

Fountoukis, C. and A. Nenes, A.: Continued Development of a Cloud Droplet Formation Parameterization for Global Climate Models, J. Geophys. Res., 110, D11212, doi:10.1029/2004JD005591, 2005.

Fountoukis, C. and Nenes, A.: ISORROPIA II: a computationally efficient thermodynamic equilibrium model for $\mathrm{K}^{+}$ $\mathrm{Ca}^{2+}-\mathrm{Mg}^{2+}-\mathrm{NH}_{4}^{+}-\mathrm{Na}^{+}-\mathrm{SO}_{4}^{2-}-\mathrm{NO}_{3}^{-}-\mathrm{Cl}^{-}-\mathrm{H}_{2} \mathrm{O}$ aerosols, Atmos. Chem. Phys., 7, 4639-4659, doi:10.5194/acp-7-4639-2007, 2007.

Ghan, S. J., Abdul-Razzak, H., Nenes, A., Ming, Y., Liu, X., Ovchinnikov, M., Shipway, B., Meskhidze, N., Xu, J., and Shi, X.: Droplet Nucleation: Physically-based Parameterization and Comparative Evaluation, J. Adv. Model. Earth Syst., 3, M10001, doi:10.1029/2011MS000074, 2011.

Ghate, V. P., Miller, M. A., and DiPretore, L.: Vertical velocity structure of marine boundary layer trade wind cumulus clouds, J. Geophys. Res., 116, 2156-2202, doi:10.1029/2010JD015344, 2011.

Guo, H., Xu, L., Bougiatioti, A., Cerully, K. M., Capps, S. L., Hite Jr., J. R., Carlton, A. G., Lee, S.-H., Bergin, M. H., Ng, N. L., Nenes, A., and Weber, R. J.: Fine-particle water and $\mathrm{pH}$ in the southeastern United States, Atmos. Chem. Phys., 15, 5211-5228, doi:10.5194/acp-15-5211-2015, 2015.

Hildebrandt, L., Engelhart, G. J., Mohr, C., Kostenidou, E., Lanz, V. A., Bougiatioti, A., DeCarlo, P. F., Prevot, A. S. H., Baltensperger, U., Mihalopoulos, N., Donahue, N. M., and Pandis, S. N.: Aged organic aerosol in the Eastern Mediterranean: the Finokalia Aerosol Measurement Experiment - 2008, Atmos. Chem. Phys., 10, 4167-4186, doi:10.5194/acp-10-4167-2010, 2010.

Jacobson, M. Z.: Analysis of aerosol interactions with numerical techniques for solving coagulation, nucleation, condensation, dissolution, and reversible chemistry among multiple size distributions, J. Geophys. Res. Atmospheres, 107, AAC 2-1-AAC 2-23, 2002.

Kalivitis, N., Gerasopoulos, E., Vrekoussis, M., Kouvarakis, G., Kubilay, N., Hatzianastassiou, N., Vardavas, I., and Mihalopoulos, N.: Dust transport over the eastern Mediterranean derived from Total Ozone Mapping Spectrometer, Aerosol Robotic Network, and surface measurements, J. Geophys. Res.-Atmos., 112, D03202, doi:10.1029/2006JD007510, 2007.

Kalivitis, N., Kerminen, V.-M., Kouvarakis, G., Stavroulas, I., Bougiatioti, A., Nenes, A., Manninen, H. E., Petäjä, T., Kulmala, M., and Mihalopoulos, N.: Atmospheric new particle formation as a source of $\mathrm{CCN}$ in the eastern Mediterranean marine boundary layer, Atmos. Chem. Phys., 15, 9203-9215, doi:10.5194/acp15-9203-2015, 2015.

Kalkavouras, P., Bossioli, E., Bezantakos, S., Bougiatioti, A., Kalivitis, N., Stavroulas, I., Kouvarakis, G., Protonotariou, A. P., Dandou, A., Biskos, G., Mihalopoulos, N., Nenes, A., and Tombrou, M.: New Particle Formation in the South Aegean Sea during the Etesians: importance for $\mathrm{CCN}$ production and cloud droplet number, Atmos. Chem. Phys. Discuss., doi:10.5194/acp2016-330, in review, 2016.

Kanakidou, M., Seinfeld, J. H., Pandis, S. N., Barnes, I., Dentener, F. J., Facchini, M. C., Van Dingenen, R., Ervens, B., Nenes, A., Nielsen, C. J., Swietlicki, E., Putaud, J. P., Balkanski, Y., Fuzzi, 
S., Horth, J., Moortgat, G. K., Winterhalter, R., Myhre, C. E. L., Tsigaridis, K., Vignati, E., Stephanou, E. G., and Wilson, J.: Organic aerosol and global climate modelling: a review, Atmos. Chem. Phys., 5, 1053-1123, doi:10.5194/acp-5-1053-2005, 2005.

Kaufman, Y. J. and Remer, L. A.: Detection of forests using MIDIR reflectance-An application for aerosol studies, IEEE Trans. Geosci. Remote Sens., 32, 672-683, 1994.

Knutson, E. O. and Whitby, K. T.: Aerosol classification by electric mobility: Apparatus, theory, and applications, J. Aerosol Sci., 6, 443-451, 1975.

Kyzirakos, K., Karpathiotakis, M., Garbis, G., Nikolaou, C., Bereta, K., Papoutsis, I., Herekakis, T., Michail, D., Koubarakis, M., and Kontoes, C.: Wild fire monitoring using satellite images, ontologies and linked geospatial data, Web Semantics: Science, Services and Agents on the World Wide Web, 24, 18-26, 2014.

Lance, S.: Quantifying compositional impacts of ambient aerosol on cloud droplet formation, Published Doctoral Thesis, available at: http://hdl.handle.net/1853/26700, 2007.

Lance, S., Raatikainen, T., Onasch, T. B., Worsnop, D. R., Yu, X.-Y., Alexander, M. L., Stolzenburg, M. R., McMurry, P. H., Smith, J. N., and Nenes, A.: Aerosol mixing state, hygroscopic growth and cloud activation efficiency during MIRAGE 2006, Atmos. Chem. Phys., 13, 5049-5062, doi:10.5194/acp-13-5049-2013, 2013.

Levin, E. J. T., Prenni, A. J., Petters, M. D., Kreidenweis, S. M., Sullivan, R. C., Atwood, S. A., Ortega, J., DeMott, P. J., and Smith, J. N.: An annual cycle of size-resolved aerosol hygroscopicity at a forested site in Colorado, J. Geophys. Res., 117, D06201, doi:10.1029/2011JD016854, 2012.

Liu, H. J., Zhao, C. S., Nekat, B., Ma, N., Wiedensohler, A., van Pinxteren, D., Spindler, G., Müller, K., and Herrmann, H.: Aerosol hygroscopicity derived from size-segregated chemical composition and its parameterization in the North China Plain, Atmos. Chem. Phys., 14, 2525-2539, doi:10.5194/acp-14-25252014, 2014.

Mamouri, R. E., Amiridis, V., Papayannis, A., Giannakaki, E., Tsaknakis, G., and Balis, D. S.: Validation of CALIPSO spaceborne-derived attenuated backscatter coefficient profiles using a ground-based lidar in Athens, Greece, Atmos. Meas. Tech., 2, 513-522, doi:10.5194/amt-2-513-2009, 2009.

Mamouri, R. E., Papayannis, A., Amiridis, V., Müller, D., Kokkalis, P., Rapsomanikis, S., Karageorgos, E. T., Tsaknakis, G., Nenes, A., Kazadzis, S., and Remoundaki, E.: Multi-wavelength Raman lidar, sun photometric and aircraft measurements in combination with inversion models for the estimation of the aerosol optical and physico-chemical properties over Athens, Greece, Atmos. Meas. Tech., 5, 1793-1808, doi:10.5194/amt-5-1793-2012, 2012

Massoli, P., Lambe, A. T., Ahern, A. T., Williams, L. R., Ehn, M., Mikkilä, J., Canagaratna, M.R., Brune, W. H., Onasch, T. B., Jayne, J. T., Petäjä, T., Kulmala, M., Laaksonen, A., Kolb, C.E., Davidovits, 5 P., and Worsnop, D. R.: Relationship between aerosol oxidation level and hygroscopic properties of laboratory generated secondary organic aerosol (SOA) particles, Geophys. Res. Lett., 37, L24801, doi:10.1029/2010GL045258, 2010.

Meskhidze, N., Nenes, A., Conant, W. C., and Seinfeld, J. H.: Evaluation of a new Cloud Droplet Activation Parameterization with In Situ Data from CRYSTAL-FACE and CSTRIPE, J. Geoph. Res., 110, D16202, doi:10.1029/2004JD005703, 2005.
Mihalopoulos, N., Stephanou, E., Kanakidou, M., Pilitsidis, S., and Bousquet, P.: Tropospheric aerosol ionic composition above the Eastern Mediterranean area, Tellus, 49B, 314-326, 1997.

Moore, R. H. and Nenes, A.: Scanning Flow CCN Analysis - A Method for Fast Measurements of CCN Spectra, Aersol. Sci. Tech., 43, 1192-1207, 2009.

Moore, R. H., Cerully, K., Bahreini, R., Brock, C. A., Middelbrook, A. M., and Nenes, A.: Hygroscopicity and composition of California CCN during summer 2010, J. Geophys. Res., 117, D00V12, doi:10.1029/2011JD017352, 2012a.

Moore, R. H., Raatikainen, T., Langridge, J. M., Bahreini, R., Brock, C. A., Holloway, J. S., Lack, D. A., Middlebrook, A. M., Perring, A. E., Schwarz, J. P., Spackman, J. R., and Nenes, A.: CCN spectra, hygroscopicity, and droplet activation kinetics of Secondary Organic Aerosol resulting from the 2010 Deepwater Horizon oil spill, Environ. Sci. Technol., 46, 3093-3100, 2012b.

Moore, R. H., Karydis, V. A., Capps, S. L., Lathem, T. L., and Nenes, A.: Droplet number uncertainties associated with CCN: an assessment using observations and a global model adjoint, Atmos. Chem. Phys., 13, 4235-4251, doi:10.5194/acp-13-42352013, 2013.

Morales, R. and Nenes, A.: Characteristic updrafts for computing distribution-averaged cloud droplet number, autoconversion rate effective radius, J. Geophys. Res., 115, D18220, doi:10.1029/2009JD013233, 2010.

Morales Betancourt, R. and Nenes, A.: Droplet activation parameterization: the population-splitting concept revisited, Geosci. Model Dev., 7, 2345-2357, doi:10.5194/gmd-7-2345-2014, 2014.

Nenes, A. and Seinfeld, J. H.: Parameterization of cloud droplet formation in global climate models J. Geophys. Res., 108, 4415, doi:10.1029/2002JD002911, 2003.

Ng, N. L., Herndon, S. C., Trimborn, A., Canagaratna, M. R., Croteau, P. L., Onasch, T. B., Sueper, D., Worsnop, D. R., Zhang, Q., Sun, Y. L., and Jayne, J. T.: An Aerosol Chemical Speciation Monitor (ACSM) for routine monitoring of the composition and mass concentration of ambient aerosol., Aerosol Sci. Tech., 45, 780-794, 2011.

Omar, A. H., Winker, D. M., Kittaka, C., Vaughan, M. A., Liu, Z. Y., Hu, Y. X., Trepte, C. R., Rogers, R. R., Ferrare, R. A., Lee, K. P., Kuehn, R. E., and Hostetler, C. A.: The CALIPSO automated aerosol classification and lidar ratio selection algorithm, J. Atmos. Ocean. Tech., 26, 1994-2014, doi:10.1175/2009jtecha1231.1, 2009.

Paramonov, M., Aalto, P. P., Asmi, A., Prisle, N., Kerminen, V.M., Kulmala, M., and Petäjä, T.: The analysis of size-segregated cloud condensation nuclei counter (CCNC) data and its implications for cloud droplet activation, Atmos. Chem. Phys., 13, 10285-10301, doi:10.5194/acp-13-10285-2013, 2013.

Petters, M. D. and Kreidenweis, S. M.: A single parameter representation of hygroscopic growth and cloud condensation nucleus activity, Atmos. Chem. Phys., 7, 1961-1971, doi:10.5194/acp-71961-2007, 2007.

Petters, M. D., Wex, H., Carrico, C. M., Hallbauer, E., Massling, A., McMeeking, G. R., Poulain, L., Wu, Z., Kreidenweis, S. M., and Stratmann, F.: Towards closing the gap between hygroscopic growth and activation for secondary organic aerosol - Part 2: Theoretical approaches, Atmos. Chem. Phys., 9, 3999-4009, doi:10.5194/acp-9-3999-2009, 2009. 
Pilinis, C., Pandis, S. N., and Seinfeld, J. H.: Sensitivity of direct climate forcing by atmospheric aerosols to aerosol size and composition, J. Geophys. Res., 100, 18739-18754, 1995.

Prenni, A. J., Petters, M. D., Kreidenweis, S. M., DeMott, P. J., and Ziemann, P. J.: Cloud droplet activation of secondary organic aerosol, J. Geophys. Res., 112, D10223, doi:10.1029/2006JD007963, 2007.

Rader, D. J. and McMurry, P. H.: Application of the tandem differential mobility analyzer to studies of droplet growth or evaporation, J. Aerosol Sci., 17, 771-787, 1986.

Remy, S. and Kaiser, J. W.: Daily global fire radiative power fields estimation from one or two MODIS instruments, Atmos. Chem. Phys., 14, 13377-13390, doi:10.5194/acp-14-13377-2014, 2014.

Rissler, J., Vestin, A., Swietlicki, E., Fisch, G., Zhou, J., Artaxo, P., and Andreae, M. O.: Size distribution and hygroscopic properties of aerosol particles from dry-season biomass burning in Amazonia, Atmos. Chem. Phys., 6, 471-491, doi:10.5194/acp6-471-2006, 2006.

Roberts, G., Nenes, A., Andreae, M. O., and Seinfeld, J. H.: Impact of Biomass Burning on Cloud Properties in the Amazon Basin, J. Geophys. Res., 108, 4062, doi:10.1029/2001JD000985, 2003.

Roberts, G. C. and Nenes, A.: A continuous-flow streamwise thermal-gradient $\mathrm{CCN}$ chamber for atmospheric measurements, Aerosol Sci. Tech., 39, 206-221, doi:10.1080/027868290913988, 2005.

Rose, D., Nowak, A., Achtert, P., Wiedensohler, A., Hu, M., Shao, M., Zhang, Y., Andreae, M. O., and Pöschl, U.: Cloud condensation nuclei in polluted air and biomass burning smoke near the mega-city Guangzhou, China - Part 1: Size-resolved measurements and implications for the modeling of aerosol particle hygroscopicity and CCN activity, Atmos. Chem. Phys., 10, 33653383, doi:10.5194/acp-10-3365-2010, 2010.

Ruehl, C., Chuang, P. Y., Nenes, A., Cappa, C., and Kolesar, K.: New Evidence of Surface Tension Reduction in Microscopic Aqueous Droplets, Geoph. Res. Let., 39, L23801, doi:10.1029/2012GL053706, 2012.

Sandradewi, J., Prevot, A. S. H., Szidat, S., Perron, N., Lanz, V. A., Weingartner, E., and Baltensperger, U.: Using aerosol light absorption measurements for the quantitative determination of wood burning and traffic emission contributions to particulate matter, Environ. Sci. Technol., 42, 3316-3323, 2008.

Sciare, J., Bardouki, H., Moulin, C., and Mihalopoulos, N.: Aerosol sources and their contribution to the chemical composition of aerosols in the Eastern Mediterranean Sea during summertime, Atmos. Chem. Phys., 3, 291-302, doi:10.5194/acp-3-291-2003, 2003.

Sciare, J., Oikonomou, K., Favez, O., Liakakou, E., Markaki, Z., Cachier, H., and Mihalopoulos, N.: Long-term measurements of carbonaceous aerosols in the Eastern Mediterranean: evidence of long-range transport of biomass burning, Atmos. Chem. Phys., 8, 5551-5563, doi:10.5194/acp-8-5551-2008, 2008.
Seinfeld, J. H. and Pandis, S. N.: Atmospheric Chemistry and Physics: From Air Pollution to Climate Change, 2nd Edn., J. Wiley, New York, 2006.

Spracklen, D. V., Carslaw, K. S., Pöschl, U., Rap, A., and Forster, P. M.: Global cloud condensation nuclei influenced by carbonaceous combustion aerosol, Atmos. Chem. Phys., 11, 9067-9087, doi:10.5194/acp-11-9067-2011, 2011.

Stolzenburg, M. R. and McMurry, P. H.: TDMAFIT User's Manual, Particle Technology Laboratory, Department of Mechanical Engineering, U of Minnesota, Minneapolis, MN 55455, 1988.

Stolzenburg, M. R. and McMurry, P. H.: An ultrafine aerosol Condensation Nucleus Counter, Aerosol Sci. Tech., 14, 48-65, 1991.

Triantafyllou, E., Giamarelou, M., Bossioli, E., Zarmpas, P., Theodosi, C., Matsoukas, C., Tombrou, M., Mihalopoulos, N., and Biskos, G.: Particulate Pollution Transport Episodes from Eurasia to a Remote Region of Northeast Mediterranean, Atmos. Environ., 128, 45-52, doi:10.1016/j.atmosenv.2015.12.054, 2016.

Wiedensohler, A., Birmili, W., Nowak, A., Sonntag, A., Weinhold, K., Merkel, M., Wehner, B., Tuch, T., Pfeifer, S., Fiebig, M., Fjäraa, A. M., Asmi, E., Sellegri, K., Depuy, R., Venzac, H., Villani, P., Laj, P., Aalto, P., Ogren, J. A., Swietlicki, E., Williams, P., Roldin, P., Quincey, P., Hüglin, C., Fierz-Schmidhauser, R., Gysel, M., Weingartner, E., Riccobono, F., Santos, S., Grüning, C., Faloon, K., Beddows, D., Harrison, R., Monahan, C., Jennings, S. G., O’Dowd, C. D., Marinoni, A., Horn, H.-G., Keck, L., Jiang, J., Scheckman, J., McMurry, P. H., Deng, Z., Zhao, C. S., Moerman, M., Henzing, B., de Leeuw, G., Löschau, G., and Bastian, S.: Mobility particle size spectrometers: harmonization of technical standards and data structure to facilitate high quality long-term observations of atmospheric particle number size distributions, Atmos. Meas. Tech., 5, 657-685, doi:10.5194/amt5-657-2012, 2012.

Winker, D. M., Vaughan, M. A., Omar, A., Hu, Y., Powell, K. A., Liu, Z., Hunt, W. H., and Young, S. A.: Overview of the CALIPSO mission and CALIOP data processing algorithms, J. Atmos. Ocean. Tech., 26, 2310-2323, doi:10.1175/2009JTECHA1281.1, 2009.

Wu, Z. J., Poulain, L., Henning, S., Dieckmann, K., Birmili, W., Merkel, M., van Pinxteren, D., Spindler, G., Müller, K., Stratmann, F., Herrmann, H., and Wiedensohler, A.: Relating particle hygroscopicity and $\mathrm{CCN}$ activity to chemical composition during the HCCT-2010 field campaign, Atmos. Chem. Phys., 13, $7983-$ 7996, doi:10.5194/acp-13-7983-2013, 2013.

Zamora, L. M., Kahn, R. A., Cubison, M. J., Diskin, G. S., Jimenez, J. L., Kondo, Y., McFarquhar, G. M., Nenes, A., Thornhill, K. L., Wisthaler, A., Zelenyuk, A., and Ziemba, L. D.: Aircraftmeasured indirect cloud effects from biomass burning smoke in the Arctic and subarctic, Atmos. Chem. Phys., 16, 715-738, doi:10.5194/acp-16-715-2016, 2016. 